\title{
The Market for Used Capital: Endogenous Irreversibility and Reallocation over the Business Cycle
}

\author{
Andrea Lanteri
}

Duke University

January 2016

ERID Working Paper Number 207

This paper can be downloaded without charge from the Social

Science Research Network Electronic Paper Collection:

http://ssrn.com/abstract=2733849

\section{Economic Research Initiatives at Duke WORKING PAPERS SERIES

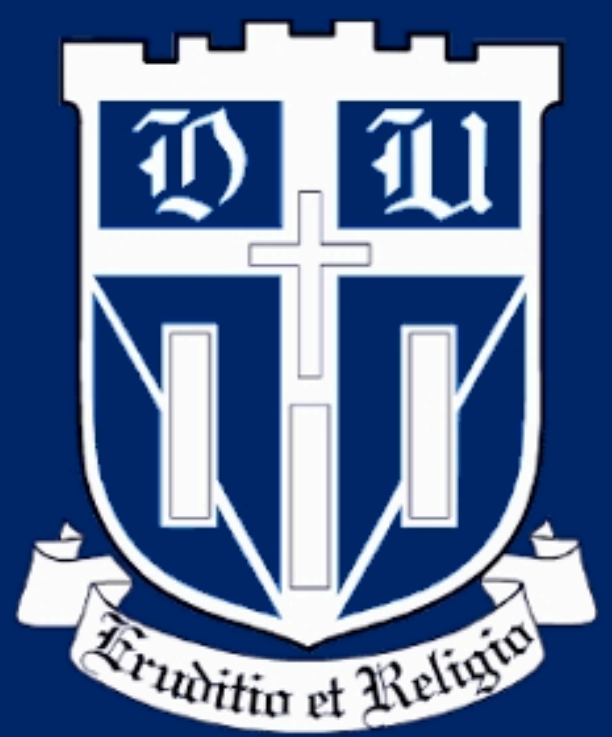




\title{
The Market for Used Capital
}

\section{Endogenous Irreversibility and Reallocation over the Business Cycle}

\author{
Andrea Lanteri*
}

January 2016

\begin{abstract}
Capital reallocation is procyclical in the data, but countercyclical in standard businesscycle models. To solve this puzzle, I build a model of endogenous partial irreversibility, with heterogeneous firms facing aggregate and idiosyncratic productivity shocks. Used investment goods are imperfect substitutes for new ones because of firm-level capital specificity. The price of used capital responds to aggregate shocks, leading to equilibrium real-option effects on investment and reallocation. The model generates procyclical capital reallocation and procyclical price of used capital, consistent with new industrylevel evidence I present, and provides a microfoundation for both micro and macro capital adjustment costs.
\end{abstract}

\section{Introduction}

Firms trade large amounts of used investment goods both directly on secondary markets for equipment and plants and indirectly through acquisitions. Over the business cycle, this

*Department of Economics, Duke University. Email: andrea.lanteri@duke.edu. Acknowledgements: I thank Wouter den Haan for great advice and very detailed comments on earlier drafts. I appreciate helpful comments from seminar participants at LSE, SED 2013, UAB, Macro-Dynamics Workshop (Bologna, 2013), MMF-Warwick PhD Workshop 2014, McGill, HEC Montreal, Michigan State, Georgetown, Duke Economics and Fuqua, CREI, TSE, Cambridge, U of Michigan, USC, U of Virginia, Minnesota Junior Finance Conference 2015. I benefited from fruitful conversations with Nick Bloom, Andrea Caggese, Julieta Caunedo, Alex Clymo, Allan Collard-Wexler, Sergio de Ferra, Davide Debortoli, Andrea Eisfeldt, Esther Hauk, Hugo Hopenhayn, Joachim Jungherr, Aubhik Khan, Pablo Kurlat, Albert Marcet, Rigas Oikonomou, Adriano Rampini and Matthew Shapiro. Finally, I am indebted to Alessandro Gavazza for his comments and encouragement and for the aircraft dataset, to Jesse Edgerton for sharing his construction equipment price index, to Clarkson and VesselsValue for the data on ships and to Andrea Eisfeldt for making reallocation data easily available on her webpage. All errors are my own. 
volume of capital reallocation is volatile and positively correlated with aggregate output. ${ }^{1}$ Why is capital reallocation procyclical? What can we learn from these data about the nature of the frictions preventing equalization of marginal products? How do equilibrium dynamics in the market for used capital affect aggregate variables such as TFP and investment? This paper addresses these questions by first showing new evidence on prices of used real assets and then building a dynamic general equilibrium model with heterogeneous firms facing aggregate and idiosyncratic uncertainty.

The market for used capital reallocates assets from less productive to more productive firms (Maksimovic and Phillips, 2011). Hence, more reallocation in booms means that more capital flows to highly productive firms when the economy is expanding, while downturns are associated with a smaller flow of assets to their most productive use. This suggests that understanding the cyclicality of capital reallocation may be a step towards a theory of cyclical movements in aggregate TFP. Consistent with this view, UK policy-makers have pointed to a lack of capital reallocation as an explanation for low aggregate productivity in the aftermath of the Great Recession (Broadbent, 2012; Barnett et al., 2014).

However, despite its relevance, the procyclicality of capital reallocation has remained a puzzle for the macroeconomic literature, for at least two reasons. First, as I will argue in this paper, existing DSGE models of investment with heterogeneous firms (e.g., Khan and Thomas, 2008, 2013) generate a negative correlation between output and reallocation, following aggregate TFP shocks. Unproductive firms want to disinvest by a larger amount in recessions because their profitability is lower following a negative aggregate productivity shock. In these one-sector models of the economy, demand for their used capital comes from both consumers and other firms. Moreover, this demand is perfectly elastic, as the standard assumption is either full reversibility of investment or a constant level of partial irreversibility, i.e., the relative price of used capital is assumed to be constant and less than one. Hence, an outward shift in the supply of used capital from disinvesting firms necessarily leads to higher sales of used capital. This means more reallocation in recessions and less in booms. Second, as Eisfeldt and Rampini (2006) point out, several measures of dispersion of returns on capital are higher in recessions than in booms, suggesting that benefits from reallocation are countercyclical. Thus, we should expect to see more reallocation during downturns, when higher dispersion makes reallocation of capital more beneficial.

In order to explain the puzzle, this paper starts by presenting new industry-level evidence

\footnotetext{
${ }^{1}$ Eisfeldt and Rampini (2006) show that reallocation of physical capital among US firms, which amounts to approximately $30 \%$ of total capital expenditures, is strongly procyclical. The cyclical component of their reallocation series, composed of Sales of Plants, Property and Equipment plus Acquisitions from Compustat, is highly volatile (about ten times the volatility of output) and positively correlated with US GDP (with a correlation coefficient of .7). Other measures of capital reallocation point to the same stylized fact: sales of used corporate assets for the UK from the ONS Capital Expenditure Survey are also procyclical, and more disaggregated evidence on the market for used commercial ships shows the same pattern of cyclicality. Section 2 and Appendix A present the empirical evidence.
} 
on the prices at which used assets are reallocated. I show time series for prices of new and used investment goods for four types of capital that are actively traded on secondary markets: aircraft, ships, vehicles and construction equipment. For all these types of assets, the relative price of used capital goods, far from being constant - as typically assumed - is actually volatile and procyclical, suggesting that partial investment irreversibility is largely a market equilibrium outcome that depends on aggregate conditions in the economy. Recessions are bad times to disinvest, as more firms would like to sell their assets to downsize, but the demand side coming from investing firms is weak.

Starting with this new stylized fact, the main contribution of this paper is to build a dynamic general equilibrium model of partially irreversible investment in which the resale price of capital is endogenous. I assume a degree of capital specificity at the firm level: after installation, capital becomes a different good with respect to the output (and consumption) good, partially specific to the firm that owns it. Not only is used capital useless for consumers, but also an imperfect substitute with respect to new investment for other firms. This assumption allows me to rationalize the procyclicality of the resale price and capital reallocation in an otherwise standard business-cycle model. In a recession, used capital is relatively cheap because more firms would like to disinvest and downsize, while expanding firms cannot fully benefit from the abundance of used capital on the market because this capital is, to an important extent, specific to the firms that operated it previously.

The model emphasizes both a static and a dynamic real-options mechanism that induce procyclical reallocation. Consider the static mechanism first. After a negative aggregate productivity shock there are two opposing forces on the disinvestment decision: on the one hand, the firm's internal value of capital falls (as in existing models); on the other hand, in this model, its market value also falls. In equilibrium, when new and used capital are sufficiently poor substitutes, the latter effect dominates, and sales of used capital fall. Next, I introduce the dynamic real-options effects. In a dynamic environment, a downsizing firm needs to compare the price at which it can sell its assets in the current period with the price it would get by waiting one more period. In a downturn, the current resale price falls. However, as long as there is some probability of exiting the recession in the near future, the future expected resale price falls by less than the current price, and it may be optimal to wait, hold on to the assets and disinvest later at a higher price. This equilibrium real-option effect further decreases the reallocation of capital in recessions.

These two mechanisms generate a countercyclical dispersion of returns from capital, because large unproductive firms downsize by less in recessions and their marginal product remains low relative to that of more productive firms. Hence, the present paper shows that the lack of reallocation and high dispersion of returns in recessions are not necessarily related to financial conditions. They emerge as equilibrium outcomes in an economy in which capital is partially specific at the firm level and used assets are imperfect substitutes for new ones. It should be noted that reallocation has fallen in every recession since we have data for it (since the 1970s), including in recessions for which the financial component was arguably 
less important than in the Great Recession. In this sense, a key contribution of this paper is to present a real model in which a single aggregate shock can generate both standard business-cycle facts and procyclical reallocation.

Furthermore, an explicit modelling of secondary markets for capital generates equilibrium effects on the primary decision to build new capital and, hence, on aggregate investment. In the quantitative section of the paper, I show that one of the aggregate implications of endogenous irreversibility is to smooth the aggregate investment series, bringing its volatility and autocorrelation closer to the empirical counterparts. Therefore, the mechanism presented in the paper constitutes a plausible microfoundation for an aggregate capital adjustment cost.

\section{Related Literature}

This paper is related to several strands of literature. First, two seminal papers analyze capital reallocation. Ramey and Shapiro (2001) study the reallocation of capital previously operated by closing aerospace plants and report the resale prices of the reallocated assets. In so doing, they provide evidence for a substantial degree of partial irreversibility in secondary markets. In this paper, I look at several other industries and construct or gather measures of resale prices over the business cycle. By looking at industries that allow a direct comparison of the price of new and used assets, I establish that partial irreversibility is, to a large extent, a market equilibrium outcome that varies significantly with aggregate shocks. Using Compustat data, Eisfeldt and Rampini (2006) show that Sales of Plants, Property and Equipment and Acquisitions are highly procyclical and argue that this is a puzzle, given that the benefits from reallocation, as measured, for instance, by dispersion in TFP or in utilization rates, appear to be countercyclical. Their conclusion is that there must be a countercyclical degree of reallocation frictions. The present paper establishes a microfoundation for this result by explicitly modelling a market for used capital and showing that the investment becomes endogenously more irreversible in downturns.

Second, this paper contributes to the growing literature on firm dynamics and adjustment costs in macroeconomic models. The empirical evidence on the price of used capital fills a gap in the empirical literature on capital adjustment costs. Inferences on investment irreversibility are typically indirect, based on firms' investment and disinvestment rates rather than directly on prices (e.g., Cooper and Haltiwanger, 2006). Moreover, in the theoretical literature, irreversibility is generally modelled as a constant technological friction, as in Khan and Thomas (2013) and Cui (2014). Both these papers build DSGE models with heterogeneous firms that feature constant partial irreversibility (defined by a constant resale price of capital below one) and collateral constraints. When fed with aggregate TFP shocks, these models predict countercyclical reallocation, because disinvesting firms face a constant resale price and disinvest by more in recessions than in booms. Cui (2014) shows that the procyclicality of reallocation can be obtained by introducing credit shocks - i.e., an exogenous tightening of the borrowing constraint. After such shocks, unproductive firms hold on to their capital and use its return to deleverage. Because of its differential response to TFP and credit shocks, 
capital reallocation is then used to identify these two shocks separately. Two other papers relate cyclical changes in the cross-sectional allocation of capital to financial conditions: Chen and Song (2013) build a model where financial frictions lead to countercyclical dispersion of marginal products of capital following news shock; Ai, Li and Yang (2015) show how shocks to agency frictions in a model of financial intermediation lead to more capital misallocation in downturns.

In this paper, I argue that once the price of used capital is endogenized, capital reallocation becomes procyclical in response to aggregate TFP shocks. Clearly, this result does not imply that financial frictions and credit shocks are not important in driving the allocation of capital. However, it suggests that procyclical reallocation is less of a puzzle, as it can be rationalized in a standard model in which a single aggregate shock drives both standard business-cycle facts and reallocation. Furthermore, this result suggests that the cyclicality of capital reallocation should not be interpreted as strong evidence in favor of a particular type of shock or in favor of the role of financial frictions in business-cycle dynamics. ${ }^{2}$ In this sense, this paper is related to Asker et al. (2014), who show that static measures of cross-sectional dispersion in marginal products do not necessarily provide evidence for "misallocation" in a welfare sense in models with investment adjustment costs. Consistent with their result, the present paper suggests that time-series variation in the dispersion of marginal products also does not necessarily imply that the allocation improves or worsens in a welfare sense over time. ${ }^{3}$ Moreover, the present model provides a framework that is very suitable to being extended to include financial frictions in the form of collateral constraints. Following aggregate shocks, the availability of credit would change endogenously with movements in the price of used capital. $^{4}$

Third, this paper contributes to the large literature (both in economics and finance) on real options, starting with the seminal work of Dixit and Pindyck (1994) and Abel et al. (1996). This body of work typically assumes exogenous (possibly stochastic) paths for the prices at which a firm can buy and sell capital. ${ }^{5}$ In the literature, the resale price is assumed to be strictly less than the buying price; hence, part of the investment is sunk, and uncertainty regarding future productivity leads to the presence of option values connected with the opportunity to wait and invest in the future. This paper contributes to this literature

\footnotetext{
${ }^{2}$ I Appendix E I show that the main mechanism is also robust to investment-specific productivity shocks.

${ }^{3}$ Relatedly, Caunedo (2015) shows that a social planner would optimally induce a positive and time-varying dispersion of marginal products in a model with non-convexities in investment and aggregate shocks.

${ }^{4}$ Other related papers with heterogeneous firms include Cooper and Schott (2013), who introduce exogenous shocks to firms' opportunity to reallocate capital, Gilchrist et al. (2014), who model the resale price of capital as an exogenous shock, and Ottonello (2015), who emphasizes the role of financial shocks and search frictions in capital reallocation. Osotimehin (2013) estimates distortions in reallocation of factors using French firm-level data for the period 1991-2006 and finds that in that sample reallocation contributed to alleviate the cyclicality of aggregate productivity.

${ }^{5}$ A notable exception is given by Ai and Kiku (2013), who present a model of real options with endogenous price of capital but do not consider the possibility of downsizing.
} 
by building a model of equilibrium real options, in which the prices at which firms can expand or downsize their capital stock are determined endogenously. This allows me to compute the effects of aggregate shocks on these option values through prices and to discuss how they affect investment and reallocation decisions.

Finally, the key assumption in this paper is imperfect substitutability between new and used capital. In an extreme example of this friction, Ramey and Shapiro (2001) report that during the liquidation of an aerospace plant, a firm sold a wind tunnel that could generate a $270 \mathrm{mph}$ wind to a company that rented it to bicycle helmet designers, who needed only low speeds and did not value it as much as the aerospace firm that sold it. Edgerton (2011) uses evidence from tax depreciation reforms in the US to estimate the elasticity of substitution between new and used capital in the production function and finds values in the range between one and ten for sectors such as farming, construction and aircraft. ${ }^{6}$

An alternative assumption that generates an endogenous resale price of capital is asymmetric information on capital quality - i.e., lemons problems in secondary markets (Eisfeldt, 2004; Kurlat, 2013; Li and Whited, 2014). However, note that this assumption does not necessarily induce a procyclical resale price of capital (and procyclical reallocation). In a world in which sellers of capital either sell capital of good quality because of a negative productivity shock, or they sell because their capital is of poor quality, a recession may give rise to a higher average quality of capital being sold, as more firms owning good capital would genuinely need to downsize. Furthermore, asymmetric information is unlikely to play a large role for some of the types of capital I will focus on in the empirical section - aircraft, for example. As Gavazza (2011b) argues, the maintenance record of airplanes is public information.

The rest of the paper is organized as follows. Section 2 presents data on reallocation and the price of used investment goods over the business cycle. Section 3 introduces the key model assumptions in a simple static model. Section 4 extends the model to discuss dynamics and equilibrium real-options effects. Section 5 presents a full-fledged DSGE model, and Section 6 discusses the quantitative results. Section 7 concludes.

\section{Empirical evidence}

In this section, I first discuss the empirical evidence on capital reallocation and then introduce industry-level evidence on the business-cycle dynamics of the prices at which used capital is traded. Two facts emerge: both the volume of reallocation and the price at which capital is

\footnotetext{
${ }^{6}$ Relatedly, Jovanovic and Yatsenko (2012) build a vintage capital model to study technology adoption decisions and assume that different vintages of capital enter the production function in a Constant Elasticity of Substitution (CES) form. Eisfeldt and Rampini (2007) show that in the data, firms of all sizes invest in both new and used capital and build a model assuming that new and used investment goods differ because used capital is cheaper but requires more maintenance in the future, thus inducing financially constrained firms to buy a higher ratio of used to new items.
} 
reallocated (i.e. the price of used capital) are volatile and procyclical.

\subsection{Capital reallocation}

Eisfeldt and Rampini (2006) construct a measure of capital reallocation from Compustat data by summing Sales of Plants, Property and Equipment (SPPE) and Acquisitions. Figure 1 shows the cyclical components of their capital reallocation series for the period 1971-2011. Reallocation is highly volatile (approximately ten times as volatile as US GDP) and positively correlated with output, with a correlation coefficient of .714. Standard deviations and correlation coefficients of each component of reallocation are reported in Table 6 in Appendix A. Acquisitions represent the larger component of the capital reallocation series (approximately two thirds of the total) and are also more volatile (the standard deviation of acquisitions is .221 and that of SPPE is .075). However, each of the two components taken individually is significantly procyclical. Consistently with this obervation, in the theoretical model, I will use Eisfeldt and Rampini's (2006) definition of capital reallocation and not distinguish between bundled (acquisitions) and unbundled sales of used capital. ${ }^{7}$

It should be noted that Compustat data show transaction volumes, but do not allow to distinguish between price and quantity changes. This requires more disaggregated evidence. In this sense, the market for second-hand commercial ships, which is a very active global secondary market, provides an ideal source of data on second-hand sales. Unlike Compustat data, data on trading of used ships are divided into prices and quantities traded (number of sales) and do not depend on aggregation across types of investment goods. The following picture emerges from these industry-level data: high trading volumes are associated with the period of economic expansion leading to 2007, and an abrupt fall in the number of sales coincides with the start of the Great Recession. This is illustrated in Figure 12 in Appendix A, where I also show a measure of capital reallocation for the UK (second-hand investment from the Survey of Capital Expenditures compiled by the ONS) during the Great Recession (Figure 13).

\subsection{The price of used capital}

I now present new industry-level evidence on the price of new and used investment goods and uncover a stylized fact on the resale price of capital: over the business-cycle, the price of used investment goods is more volatile than the price of new investment goods. Both the price of new and the price of used capital are procyclical. However, because the price of used capital is more volatile, the relative price of used capital (relative to new) is itself procyclical.

\footnotetext{
${ }^{7}$ Using a different data source - i.e. the Longitudinal Research Database compiled by the US Census Bureau, -Maksimovic and Phillips (2001) find that the fraction of manufacturing plants involved in M\&A activity goes from $3.89 \%$ in an average year to $6.19 \%$ in expansion years.
} 


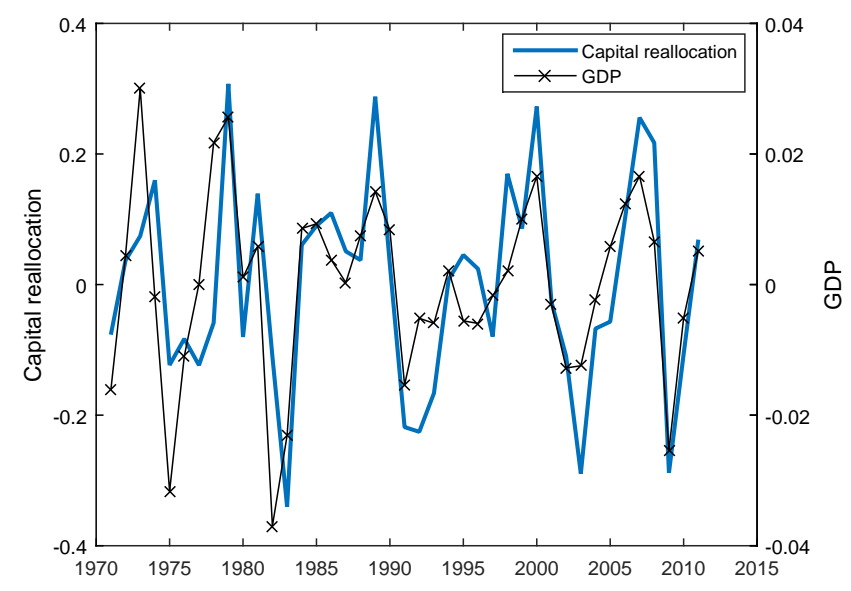

Figure 1: Capital reallocation and US GDP (cyclical components)

Log-deviations from HP trend (smoothing parameter $=6.25$ ) of (i) the Eisfeldt and Rampini (2006) capital reallocation series, composed of Sales of Property, Plants and Equipment and Acquisitions from Compustat, deflated using the US GDP deflator, (ii) US real GDP. Yearly frequency.

In order to study the business-cycle properties of the resale price of capital, I construct or gather price indices from four industries that allow a direct comparison of the value of new and used investment goods with the same characteristics, such as model and age. These are industries for which data on secondary markets are available: firms in these industries use highly tradable physical capital goods, allowing for active markets where reallocation takes place. The types of capital I study are:

- commercial aircraft

- commercial ships

- vehicles and trucks

- construction equipment

While this may be considered suggestive evidence related to specific industries, the businesscycle behavior of the prices of these types of capital is qualitatively similar, showing a stronger reaction of the price of used capital to business-cycle shocks relative to the price of new capital.

Details on data sources and construction of the price indices are reported in the empirical appendix (Appendix A). In Figure 2, I plot the price indices of new (blue solid line) and used (red dashed-dotted line) capital, in the four industries I consider. The higher volatility of the price of used capital is a common feature of the four types of capital. This is confirmed more 
formally in Table 1, where I report standard deviations and relative standard errors, as well as the correlation coefficients of the prices series with the cyclical components of US GDP. In all four industries considered, the volatility of the price of used capital is significantly larger (more than ten times as large, for construction equipment) than that of the respective price of new. Both the price of new investment goods and that of used comove positively with output (except for new vehicles, for which the correlation is not significant). However, the price of used goods shows larger fluctuations.
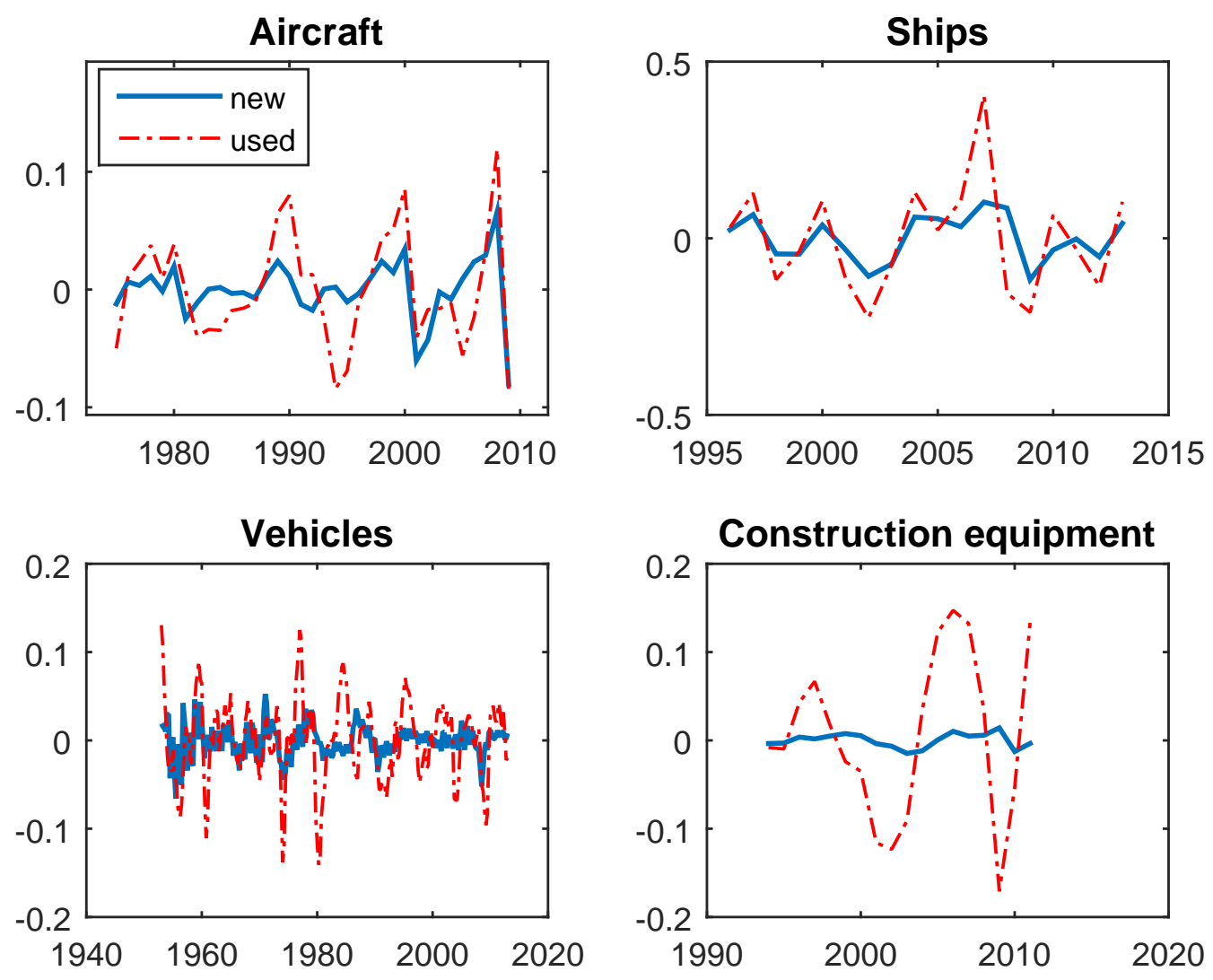

Figure 2: Prices of new and used capital (cyclical components)

Log-deviations from trend of price index of new capital and price index of used capital for the following types of capital: Aircraft (yearly frequency, HP filtered with smoothing parameter 6.25), Ships (yearly frequency, HP filtered with smoothing parameter 6.25), Vehicles (quarterly frequency, HP filtered with smoothing parameter 1600 ), Construction equipment (yearly frequency, available already linearly detrended). Details on data sources and construction are in Appendix A. 


\begin{tabular}{|c|c|c|c|}
\hline Type of capital & Statistic & Price of new & Price of used \\
\hline \hline Aircraft & $\sigma()$. & $.026(.006)$ & $.047(.006)$ \\
\hline Aircraft & corr(.,GDP) & $.526(.118)$ & $.512(.075)$ \\
\hline \hline Ships & $\sigma()$. & $.066(.006)$ & $.155(.024)$ \\
\hline Ships & $\operatorname{corr}(., \mathrm{GDP})$ & $.689(.156)$ & $.577(.104)$ \\
\hline \hline Vehicles & $\sigma()$. & $.018(.002)$ & $.045(.004)$ \\
\hline Vehicles & $\operatorname{corr}(., \mathrm{GDP})$ & $.056(.096)$ & $.134(.093)$ \\
\hline Construction equip. & $\sigma()$. & $.008(.001)$ & $.094(.015)$ \\
\hline Construction equip. & $\operatorname{corr}(., \mathrm{GDP})$ & $.249(.311)$ & $.682(.199)$ \\
\hline
\end{tabular}

Table 1: Business-cycle properties of the price of new and used aircraft

Standard deviations and correlation coefficients with US GDP of the cyclical components of the price of new and used capital. Standard errors, in parentheses, are computed using a GMM Newey-West (1987) procedure. Details on data sources and construction are in Appendix A.

\subsection{Discussion}

To what extent is the procyclicality of the volume of capital reallocation found by Eisfeldt and Rampini (2006) simply driven by cyclical movements in prices? By using the evidence on the price of used capital, it is possible to perform a back-of-the-envelope calculation to address this question. Under the assumption that the types of capital discussed above are somewhat representative for the aggregate economy, we can compare the cyclical movements in these price series (standard deviations from trend in a ballpark of 5-10\%) with those in the Eisfeldt and Rampini series (standard deviation of 15\%). This suggests that part of the volatility in the Eisfeldt and Rampini series is due to prices, but another part of this volatility is due to movements in the quantity traded. This is consistent with the direct observation of quantities traded on the market for used commercial ships, where prices and quantities show positive correlation. Furthermore, Eisfeldt and Rampini (2006) attempt to correct their measures for price effects by dividing them by the value of the stock of assets and find that these ratios are also procyclical, both for SPPE and Acquisitions.

It is worth observing that variations in the relative price of used assets are at odds with the standard assumption of perfect substitutability between new and used capital, implicit in onesector models of the economy. To see this, notice that even an infinitesimal decrease in this price would lead investing firms to jump to a corner solution and demand only used capital. This behavior is counterfactual: for instance, US Census Annual Capital Expenditures Survey (ACES) data on capital expenditures show a relatively stable ratio between used and new investment expenditures, with a standard deviation of approximately 1\% (this is illustrated in Figure 14 in Appendix A).

In contrast, the volatility of the resale price of capital is consistent with a degree of capital 
specificity, which induces an imperfect substitutability between new and used investment goods. In the case of aircraft, for instance, Gavazza (2011b) suggests a reason why capital specificity may play an important role in determining the volatility of the price of used assets. Carriers typically operate a very small number of models in order to exploit economies of scale in maintenance and staff training costs, and they are unwilling to substitute into other models when there is an increase in the supply of used aircraft due to aggregate shocks, leading to a fall in the value of used aircraft. Similar factors are likely to play a role in the other three industries considered. In the case of ships, size determines what routes are feasible, hence making ships of different sizes imperfectly substitutable. ${ }^{8}$

Overall, the empirical evidence suggests that recessions are bad times to disinvest because the resale price of capital is low. By treating the resale price as a constant parameter, the previous theoretical literature on investment irreversibility has not drawn any distinction between the case of a firm that needs to downsize during an expansion and that of a firm that needs to downsize in a downturn. However, the price of these two types of transactions can be quite different. This motivates me to build a model where the degree of reversibility of investment is an equilibrium outcome and responds to aggregate shocks.

\section{A simple model of capital reallocation}

Building on the empirical evidence presented above, this section introduces a simple static model that features imperfect substitutability between new and used investment goods and allows the derivation of analytical results on the response of capital reallocation to exogenous changes in aggregate productivity.

\subsection{Technological assumptions}

There is a continuum of firms $j \in[0,1]$, all of which are endowed with a common initial capital level $k_{0}$. They can produce a homogeneous output good with production function

$$
y_{j}=z s_{j} k_{j}^{\alpha}
$$

where $z$ is an aggregate productivity parameter, $s_{j}$ is an idiosyncratic shock with cdf $F\left(s_{j}\right)$ and $\alpha \in(0,1)$ is the returns-to-scale parameter.

\footnotetext{
${ }^{8}$ Specificity plays an important role in plants reallocation too. The sale of a GM pickup truck production plant in Shreveport, Louisiana to three-wheeled electric car manifacturer Elio Motors provides a recent example of capital reallocation with imperfect susbstitutability. Elio chose to acquire the plant because it was ready for reuse and more convenient than building a new plant from scratch. However, Elio clearly needed to replace some of the GM machinery with specific equipment for the production of its product. (source: cnn.com, April 2014)
} 
Each firm uses its specific type of capital in order to produce the output good. Before production, firms can adjust their capital level $k_{j}$ according to their productivity. Firms that decide to decrease their capital stock can sell some of their capital on the market for used capital. On the other hand, firms that decide to increase their capital level can invest using newly produced capital (supplied inelastically by a representative consumer) or used capital sold by disinvesting firms. New capital can be freely specialized. In contrast, used capital is partially specific to its previous owner. As a consequence, expanding firms cannot make the whole investment buying used capital, and they need to bundle it instead with some newly produced output good in order to make it specific to their firms. Hence, the substitutability between new and used investment goods is imperfect. This can be rationalized in a world in which investment goods needed to build a plant are of different types. Some of them are fairly generic and can be easily purchased as used and put in production in a different plant. Others have to be specifically designed for the production of a particular business line. In this environment, substitutability is imperfect and firms will be willing to substitute to more used capital only if it becomes cheaper. However, investing firms always have the choice to buy only new goods.

Formally, the investment technology for expanding firms is given by a perfect substitutes aggregator of new capital and a CES aggregator of used and new capital. ${ }^{9}$

$$
\begin{gathered}
k_{j}-k_{0}=\widetilde{i}_{j, \text { new }}+g\left(i_{j, \text { new }}, i_{j, \text { used }}\right) \\
g\left(i_{j, \text { new }}, i_{j, \text { used }}\right)=\left[\eta^{\frac{1}{\epsilon}}\left(i_{j, \text { new }}\right)^{\frac{\epsilon-1}{\epsilon}}+(1-\eta)^{\frac{1}{\epsilon}}\left(i_{j, \text { used }}\right)^{\frac{\epsilon-1}{\epsilon}}\right]^{\frac{\epsilon}{\epsilon-1}}
\end{gathered}
$$

where $\widetilde{i}_{j, \text { new }}$ and $i_{j, \text { new }}$ are new investment goods, and $i_{j, \text { used }}$ is used capital sold by disinvesting firms. $\eta \in(0,1)$ is a parameter that determines the average ratio between new and used investment, while $\epsilon>0$ is the elasticity of substitution between new and used investment goods.

The price of a unit of new capital in terms of the output good is 1 , while the cost of a unit of used capital is equal to the sum of the price of used capital $q_{t}$ and a per-unit reallocation $\operatorname{cost} \gamma$. Hence, the CES price index associated with a composite $g$ of new and used investment goods is

$$
Q=\left[\eta+(1-\eta)(q+\gamma)^{1-\epsilon}\right]^{\frac{1}{1-\epsilon}}
$$

Firms will choose the cheapest option between a fully new investment $\widetilde{i}_{j, n e w}$ and a bundle g. As long as $q<1-\gamma \Rightarrow Q<1$, the bundle is the cheapest option; hence, firms choose to make a fraction of their investment using used capital and set $\widetilde{i}_{j \text {,new }}=0$. However, if the price of used capital were to become hypothetically higher than the price of new capital, firms

\footnotetext{
${ }^{9}$ Unlike Jovanovic and Yatsenko (2012) and Edgerton (2011), and in order to make the general equilibrium model computationally tractable, I assume that imperfect substitutability is in the investment technology rather than in the production function, which allows me to endogenize the resale price while, at the same time, keeping track of only one type of capital as a state variable in the full dynamic model.
} 
would optimally buy only new capital. Throughout the paper, in equilibrium, it will always be the case that $q<1-\gamma$. Thus, I will focus on this case in the following analysis.

I interpret the elasticity $\epsilon$ as an inverse measure of capital specificity. When $\epsilon \rightarrow \infty$, new and used capital are perfect substitutes, and the model nests a standard model of partial irreversibility with constant resale price $q=1-\gamma$. When $\epsilon=0$, the technology does not allow substitutability between new and used capital.

Finally, I assume that used capital is useless for consumers. Thus, the market for used capital clears between investing and disinvesting firms only. ${ }^{10}$ This assumption is equivalent to the assumption of total irreversibility in the aggregate, as, for instance, in Sargent (1980).

\subsection{Optimal investment and reallocation decisions}

The solution to firms' optimal investment problem can be easily characterized:

- If firms are sufficiently productive, they will invest, buying a bundle of new and used capital at price $Q$. This will happen if $s_{j} \geq s^{I}=\frac{Q}{\alpha z k_{0}^{\alpha-1}}$. In this case, the optimal capital level is given by

$$
k_{j}=\left(\frac{\alpha z s_{j}}{Q}\right)^{\frac{1}{1-\alpha}} .
$$

- If firms are sufficiently unproductive, they will disinvest, selling part of their capital at price $q$. This will happen if $s_{j}<s^{D}=\frac{q}{\alpha z k_{0}^{\alpha-1}}$. In this case, the optimal capital level is given by

$$
k_{j}=\left(\frac{\alpha z s_{j}}{q}\right)^{\frac{1}{1-\alpha}} .
$$

- Firms with intermediate productivity $s^{D} \leq s_{j}<s^{I}$ will choose to keep their capital level at $k_{0}$, as their marginal product of capital lies between the purchasing price $Q$ and the selling price $q$.

\subsection{Equilibrium in the market for used capital}

Given a chosen amount of total investment, investing firms minimize their expenditures by buying a composite of new and used capital. By solving a standard CES expenditure minimization problem and integrating over the measure of investing firms, we get the total demand for used capital:

$$
D_{\text {used }}=(1-\eta)\left(\frac{q+\gamma}{Q}\right)^{-\epsilon} \int_{s^{I}}\left[\left(\frac{\alpha z s}{Q}\right)^{\frac{1}{1-\alpha}}-k_{0}\right] d F(s)
$$

\footnotetext{
${ }^{10}$ While it is true that some types of capital, such as cars and computers, could be useful for consumers after having been used by firms, for most other kinds of equipment and for plants, this is impossible.
} 
On the other hand, total supply of used capital, coming from disinvesting firms, is

$$
S_{\text {used }}=\int^{s^{D}}\left[k_{0}-\left(\frac{\alpha z s}{q}\right)^{\frac{1}{1-\alpha}}\right] d F(s) .
$$

The market-clearing condition $D_{\text {used }}=S_{\text {used }}$ implicitly defines the equilibrium price as a function of the aggregate productivity parameter $z, q=q(z ; \epsilon)$, where I emphasize that this equilibrium price mapping depends on the elasticity of substitution $\epsilon$. The following proposition relates this elasticity to the effect of aggregate shocks on irreversibility and reallocation.

Proposition 1. (i) $q(z ; \epsilon)$ is increasing in $z$. (ii) There exists an $\bar{\epsilon}>0$ such that for $\epsilon<\bar{\epsilon}$, the elasticity of $q$ with respect to $z$ is greater than 1 and reallocation is increasing in $z$.

The proof, in Appendix B, is based on an application of the Implicit Function Theorem to the market-clearing condition. To derive intuition on the mechanism, consider without loss of generality a marginal decrease in $z$. At a given resale price, disinvesting firms would like to sell more capital because their optimal target level is now lower. This implies that the supply schedule of used capital (6) shifts out in a standard price-quantity space. Similarly, investing firms want to invest less, and demand (5) shifts in. The price of used capital $q$ must fall to clear the market, and the price index of investment $Q$ will also decrease, although by less, because it is a CES average of 1 (the price of new capital) and $(q+\gamma)$. This reflects the fact that investing firms cannot fully benefit from the cheaper used capital on offer because its specificity makes it less valuable for them.

For sufficiently low elasticity of substitution, $q$ will fall by more than the initial decrease in $z$; the threshold $s^{D}=q / \alpha z k_{0}^{\alpha-1}$ will decrease; the choice of new capital level conditional on $s_{j}$ for disinvesting firms will increase, inducing less reallocation. Note that this is in contrast to a model in which the resale price is constant; in such a model, the disinvesting threshold would increase following a fall in $z$, and total reallocation would necessarily be higher.

The reaction of the resale price leads to amplification in the movements of aggregate productivity. The mechanism works as follows: measured aggregate productivity (the Solow residual obtained assuming an aggregate production function) falls by more than the initial negative shock because the decrease in trading in the market for used capital leads unproductive firms to remain large, relative to the size they would be in a world with a fixed resale price; as a consequence, firms with low productivity operate a larger fraction of aggregate capital.

Furthermore, under a suitable assumption on the distribution $F$, the model generates a countercyclical dispersion of marginal products. Assume for simplicity that $F$ is uniform on $\left[s_{\min }, s_{\max }\right]$. Consider, again, a marginal decrease in $z$. Out of the inaction region, investing firms set their marginal product equal to $Q$ and disinvesting firms set it equal to $q$. In the 
inaction region, the marginal product of each firm stays equal to its initial value. When aggregate productivity falls, the distance between $q$ and $Q$ increases, because $q$ decreases by more than $Q(Q$ is a CES average of $q+\gamma$ and 1$)$. This has two effects. First, the difference between the marginal product of investing firms and that of disinvesting firms increases. Second, the mass of firms in the inaction region increases. Both effects necessarily lead to higher dispersion of marginal products.

Figure 3 provides a graphical representation of the solution to the model and its comparative statics. Consider the upper horizontal line. Each point on the line is the marginal product of capital of a firm, evaluated at $k_{0}$. Firms with marginal product larger than $Q$ invest up to the point where their marginal product equals $Q$. Likewise, firms with initial marginal product below the resale price $q$ disinvest up to the point where their marginal product equals $q$. These investment and disinvestment decisions are represented by the curved arrows pointing towards the two prices. Firms with intermediate initial marginal product are in the inaction region and remain at $k_{0}$. The lower horizontal line corresponds to a decrease in $z$. Note that both $Q$ and $q$ decrease, but the former decreases by less than the latter. Hence, the inaction region becomes larger.

In conclusion, this simple static model shows that in an economy with a sufficient degree of capital specificity, a fall in aggregate productivity leads to an even larger decrease in the resale price of capital, a decrease in reallocation and an increase in the dispersion of marginal products.

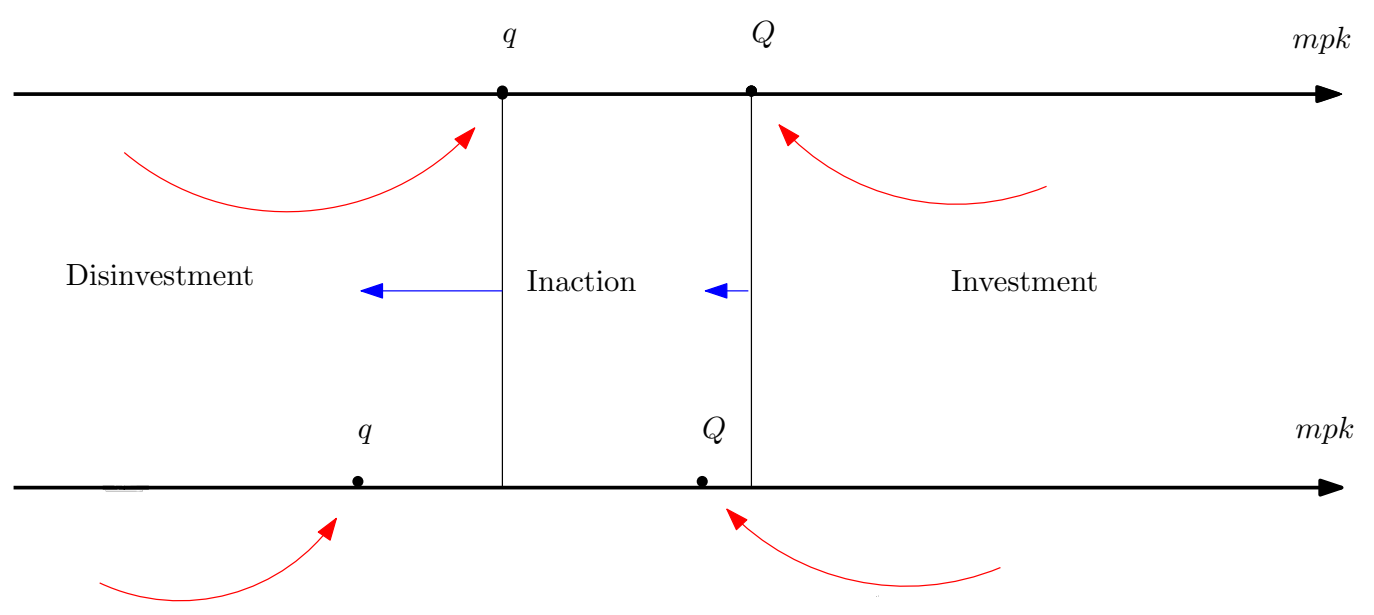

Figure 3: Graphical representation of the static mechanism

Firms' investment/disinvestment decisions and inaction region. Upper horizontal line: benchmark solution. Lower horizontal line: marginal decrease in aggregate productivity $z$. 


\section{Aggregate shocks and equilibrium real options}

This section introduces dynamics by presenting a two-period model with uncertainty and forward-looking firms, where investment and reallocation decisions depend not only on current prices, but also, importantly, on future expected prices at which firms can buy and sell investment goods. The model extends the partial equilibrium literature on real options - in particular, the seminal work of Abel et al. (1996) - by imposing equilibrium in the market for used capital. I consider a continuum of firms hit by idiosyncratic and aggregate shocks and impose that the market for used capital clears in all states. This allows me to discuss the equilibrium effects of aggregate shocks on firms' real option values in an environment in which all firms make their investment decisions taking these options into account. After a negative persistent aggregate TFP shock, capital not only is less productive, but is also perceived as more irreversible, as its expected future resale price falls. Furthermore, disinvesting firms in a recession have an incentive to wait and sell capital at a better price if the economy recovers.

\subsection{Two-period model}

There is a continuum of firms with idiosyncratic productivity $s_{j t}$ producing with technology

$$
y_{j t}=z_{t} s_{j t} k_{j t}^{\alpha}
$$

for $t=1,2$. Both $z_{t}$ and $s_{j t}$ follow a positively autocorrelated process. In particular, aggregate productivity takes either of two values $\left\{z^{L}, z^{H}\right\}$, and a Markov transition matrix gives conditional probabilities for time $t=2$. I assume that $\operatorname{Pr}\left\{z_{2}=z_{1}\right\}>1 / 2$, that is, aggregate productivity is positively autocorrelated. The idiosyncratic shock at $t=1$ is drawn from a log-normal distribution with mean $-\sigma_{1}^{2} / 2$ and variance $\sigma_{1}^{2}$. At time 2 , the shock satisfies $\log \left(s_{2}\right)=\rho \log \left(s_{1}\right)+v_{2}$, with $v_{2} \sim N\left(-\sigma_{2}^{2} / 2, \sigma_{2}^{2}\right)$

Firms start the initial period with a common level of capital $k_{0}$, observe the realizations of the two productivity shocks, $\left(s_{j 1}, z_{1}\right)$, and are allowed to choose their capital level $k_{j 1}$ before starting production. If they invest, they can purchase a combination of new and used capital, which is being sold by disinvesting firms that decide to decrease their capital level. As in the static model in the previous section, the investment technology is given by (2), and the price index of investment goods is given by (4) in both periods, except that $q$ and $Q$ will now have a $t$ subscript. The reallocation cost $\gamma$ is constant.

After the investment/disinvestment activity is concluded, production takes place. Abstracting from physical depreciation for simplicity of exposition, firms start the second period with an initial level of capital $k_{j 1}$, observe the realizations of $s_{j 2}$ and $z_{2}$ and are, again, allowed to adjust their capital level before production. Then, production takes place again and, at the end of the period, firms receive a terminal value proportional to their capital level, $\chi k_{j 2}$, with $\chi \geq 0$. 


\subsection{Value of a firm}

As long as $q_{t}<Q_{t}$, in both periods, some firms will invest, some will disinvest and some will keep their capital stock unchanged because the marginal product of their capital lies between the two prices. Let's start by characterizing the value of a firm after its choice of capital at $t=1$. The next subsection will then move backwards and solve for the optimal choice of $k_{j 1}$. By anticipating optimal behavior at $t=2$, the value of a firm can be decomposed into a component that assumes no further adjustment in the second period, a component that depends on the opportunity to buy more capital in the second period (call option) and a component that depends on the possibility of selling some capital in the second period (put option). The call option will be exercised only for sufficiently high $s_{j 2}$ and the put option only for sufficiently low $s_{j 2}$. In the following derivation I drop the subscript $j$ for notational convenience and consider a generic firm. At $t=1$, after observing the pair $\left(s_{1}, z_{1}\right)$ and choosing $k_{1}$, the value of the firm is

$$
V\left(k_{1}, s_{1}, z_{1}\right)=z_{1} s_{1} k_{1}^{\alpha}+\beta\left(\mathrm{E}_{1} z_{2} s_{2} k_{1}^{\alpha}+\chi k_{1}\right)+\beta C\left(k_{1}, s_{1}, z_{1}\right)+\beta P\left(k_{1}, s_{1}, z_{1}\right)
$$

where $\mathrm{E}_{1}$ is a conditional expectation operator that sums over the future realizations of $z$ and integrates over the distribution of $s_{2}$, conditional on $\left(s_{1}, z_{1}\right)$. The value of the firm consists of the value of producing in both periods with $k_{1}$ - i.e. without making any further adjustment at $t=2$ - plus the call option value of increasing the capital stock, $C\left(k_{1}, s_{1}, z_{1}\right)$, and the put option value of selling part of the capital stock in the second period, $P\left(k_{1}, s_{1}, z_{1}\right)$.

The call option value is given by

$$
\begin{aligned}
C\left(k_{1}, s_{1}, z_{1}\right)=\mathrm{E}_{z_{1}} \int_{s_{2}^{I}\left(k_{1}, z_{2}\right)}\left\{\left[z_{2} s_{2}(\right.\right. & \left.\left.k_{2}\left(s_{2}, z_{2}\right)\right)^{\alpha}+\chi k_{2}\left(s_{2}, z_{2}\right)\right] \\
& \left.-\left[z_{2} s_{2} k_{1}^{\alpha}+\chi k_{1}\right]-Q_{2}\left[k_{2}\left(s_{2}, z_{2}\right)-k_{1}\right]\right\} d F\left(s_{2} \mid s_{1}\right)
\end{aligned}
$$

where $\mathrm{E}_{z_{1}}$ sums over realizations of $z_{2}$, with probabilities conditional on $z_{1}$. This option will be exercised at $t=2$ if idiosyncratic productivity turns out to be above the threshold $s_{2}^{I}\left(k_{1}, z_{2}\right)=\frac{Q_{2}-\chi}{\alpha z_{2} k_{1}^{\alpha-1}}$, in which case the firm will invest and go to a capital level given by

$$
k_{2}=\left(\frac{\alpha z s_{j 2}}{Q_{2}-\chi}\right)^{\frac{1}{1-\alpha}}>k_{1}
$$

Similarly, the put option is

$$
\begin{aligned}
P\left(k_{1}, s_{1}, z_{1}\right)=\mathrm{E}_{z_{1}} \int^{s_{2}^{D}\left(k_{1}, z_{2}\right)}\left\{\left[z_{2} s_{2}(\right.\right. & \left.\left.k_{2}\left(s_{2}, z_{2}\right)\right)^{\alpha}+\chi k_{2}\left(s_{2}, z_{2}\right)\right] \\
& \left.-\left[z_{2} s_{2} k_{1}^{\alpha}+\chi k_{1}\right]+q_{2}\left[k_{1}-k_{2}\left(s_{2}, z_{2}\right)\right]\right\} d F\left(s_{2} \mid s_{1}\right)
\end{aligned}
$$


and will be exercised at $t=2$ if idiosyncratic productivity turns out to be below the threshold $s_{2}^{D}\left(k_{1}, z_{2}\right)=\frac{q_{2}-\chi}{\alpha z_{2} k_{1}^{\alpha-1}}$ by selling capital up to the level

$$
k_{2}=\left(\frac{\alpha z s_{j 2}}{q_{2}-\chi}\right)^{\frac{1}{1-\alpha}}<k_{1}
$$

It is easy to see that the value of the call option is decreasing in the realizations of $Q_{2}$, while the put option is increasing in the realizations of $q_{2}$. While a higher $Q_{2}$ makes it harder to expand tomorrow, a higher $q_{2}$ makes it easier to downsize, should doing so be desirable.

\subsection{Optimal investment and reallocation decisions}

We can now characterize the optimal choice of capital level in the first period. At $t=1$, firms compare the marginal value of their initial capital level $k_{0}$ with the purchasing price $Q_{1}$ and the selling price $q_{1}$. Call $V_{k}$ the partial derivative of $V$ with respect to its first argument.

- Firms that receive an idiosyncratic shock such that $V_{k}\left(k_{0}, s_{1}, z_{1}\right) \geq Q_{1}$ choose to invest, and their optimal capital level $k_{1}\left(s_{1}, z_{1}\right)$ satisfies

$$
\frac{V_{k}\left(k_{1}, s_{1}, z_{1}\right)}{Q_{1}}=\frac{\alpha z_{1} s_{1} k_{1}^{\alpha-1}+\alpha \beta \mathrm{E}_{1} z_{2} s_{2} k_{1}^{\alpha-1}+\beta \chi+C_{k}\left(k_{1}, s_{1}, z_{1}\right)+P_{k}\left(k_{1}, s_{1}, z_{1}\right)}{Q_{1}}=1
$$

where I have emphasized that the marginal value of capital is composed by the present discounted value of their marginal product, assuming no further adjustment, the marginal call $C_{k}$ and the marginal put $P_{k}$. Note that both the present discounted value of the marginal product and $P_{k}$ are positive, while $C_{k}$ is negative, as increasing the capital level implies exercising part of the call option value.

- For firms with sufficiently low idiosyncratic productivity, $V_{k}\left(k_{0}, s_{1}, z_{1}\right)<q_{1}$. They will disinvest and choose $k_{1}\left(s_{1}, z_{1}\right)$ by solving

$$
\frac{V_{k}\left(k_{1}, s_{1}, z_{1}\right)}{q_{1}}=\frac{\alpha z_{1} s_{1} k_{1}^{\alpha-1}+\alpha \beta \mathrm{E}_{1} z_{2} s_{2} k_{1}^{\alpha-1}+\beta \chi+C_{k}\left(k_{1}, s_{1}, z_{1}\right)+P_{k}\left(k_{1}, s_{1}, z_{1}\right)}{q_{1}}=1
$$

- Firms with intermediate productivity, such that $q_{1} \leq V_{k}\left(k_{0}, s_{1}, z_{1}\right)<Q_{1}$, are in the inaction region and optimally keep $k_{1}\left(s_{1}, z_{1}\right)=k_{0}$.

As in the static model, firms compare the marginal value of capital with $Q$ if they consider investing and with $q$ if they consider disinvesting. Different from the static model, however, this marginal value now takes into account the variations in the option values induced by such investment and disinvestment activity.

The market for used capital clears; that is, as in the static model, total disinvestment from unproductive firms equals investment in used capital coming from investing firms. 


\subsection{Equilibrium real options, investment and reallocation}

To understand how equilibrium real options affect investment and disinvestment behavior following business-cycle shocks, consider the marginal value of the put option $P_{k}{ }^{11}$ Differentiating (10) with respect to the choice of capital and writing the expectation more explicitly, we get

$$
P_{k}\left(k_{1}, s_{1}, z_{1}\right)=\sum_{z_{2} \in\left\{z^{L}, z^{H}\right\}} \operatorname{Pr}\left\{z_{2} \mid z_{1}\right\} \int^{s_{2}^{D}\left(k_{1}, z_{2}\right)}\left[q_{2}\left(z_{1}, z_{2}\right)-\alpha z_{2} s_{2} k_{1}^{\alpha-1}-\chi\right] d F\left(s_{2} \mid s_{1}\right)
$$

where I emphasize that the equilibrium resale price depends on both realizations of the aggregate shock. Hence, conditional on $z_{1}$, there are two possible outcomes for $q_{2}$, depending on the realization of $z_{2}$.

Consider the two elements of the summation over $z_{2}$. If one keeps the resale price $q_{2}$ constant, then the marginal put value of capital is unambiguously decreasing in $z_{2}$; that is, a decrease in the value of aggregate productivity necessarily leads to an increase in $P_{k}$. This is because $P_{k}$ depends negatively on the marginal product of installed capital: the less productive capital is, the higher the gain from selling it will be.

However, the expected resale price is also endogenous in this model, and this equilibrium effect goes in the opposite direction with respect to the effect of $z_{2}$. It is easy to see that $P_{k}$ is increasing in the expected value of the future resale price $q_{2}$ because this price adds value to a marginal unit of capital bought in the first period, if this unit has to be resold in the second period. This is the case because the value of a marginal unit of capital purchased in the first period depends positively on its resaleability, and, in a recession, the expected resale price falls. Thus, this indirect equilibrium effect through the price of used capital goes against the direct partial equilibrium effect.

The model has rich implications for the effects of aggregate shocks on investing and disinvesting firms. Consider expanding units first. In a boom, capital is now attractive for two reasons. First, it is directly more productive. Second, it is easier to resell, if a bad idiosyncratic shock hits the firm in the future. This effect reflects the equilibrium change in the put option value of capital. Third, it is more expensive today because the current price of used assets increases and, hence, total investment comes at a higher price. In the quantitative analysis in the next section, I will show that this last effect dominates in general equilibrium, leading to a smoothing of aggregate investment through changes in the price index of investment goods.

For disinvesting firms, the first order condition for $k_{1}$ suggests a key comparison between the marginal value of capital and the current resale price. The ratio between the present

\footnotetext{
${ }^{11}$ As the evidence presented in Section 2 suggests, the resale price of capital is more volatile and procyclical than the price of new capital. Hence, I will focus on the put option value and its reaction to shocks, although similar arguments can be made about equilibrium effects of shocks on the call option.
} 
discounted value of marginal returns and $q_{1}$ behaves similarly to the static model. Let us disregard variations in the marginal call value, as they are small, given the relatively low volatility of $Q_{t}$, and focus on the ratio $\frac{P_{k}}{q_{1}}$.

Unproductive firms compare the price that they can get for their assets at $t=1$ with the value from waiting until the second period to disinvest, which, as we have seen, is an increasing function of the expected value of $q_{2}$. This allows me to identify two forces that act in opposite directions. On the one hand, in a recession, the marginal put option falls because the resale value of capital is going to fall at $t=2$ with high probability (as the aggregate shock is persistent). This would imply that it is optimal to disinvest by more in the first period. On the other hand, the current resale price in the first period is also low. Note that, with positive probability, $z_{2}$ will be high and the resale price will increase, in which case it would be optimal to disinvest by less in the first period and wait until the second period.

Because of mean reversion of the aggregate shock process, following a low realization of the aggregate TFP shock, the fall in the current price of used capital will dominate the fall in its future expected value, generating a value of waiting to disinvest in the future, further delaying reallocation and amplifying the static effects analyzed in Section 3.

I now show a numerical example of equilibrium real-option values. Parameter values are only meant to be illustrative and are shown in Appendix C. I solve the two-period model numerically and compute option values by numerical integration. Figure 4 illustrates the payoff of the put option value in equation (10), evaluated at $k_{0}$ and at the optimal choice $k_{1}$, as a function of the initial idiosyncratic shock $s_{1}$ and for each of two values of $z_{1}$. I label the low realization of $z_{1}$ "recession" and the high realization "boom". Consider the put option before investment and disinvestment (red thick solid and blue thick dashed lines for boom and recession respectively). This option value has a similar payoff function to a financial option. In this case, the strike price is the resale price $q_{2}$ and the underlying asset value is the marginal value of the firm's capital. For a firm with very low $s_{1}, k_{0}$ is a relatively large size. Hence, if the firm does not disinvest in the first period, it is likely that some disinvestment will be optimal in the second period, given the positive autocorrelation of $s_{t}$. This explains a high put option value in the left-hand side of the figure. On the other hand, for a firm with very high $s_{1}$, the optimal size is larger than $k_{0}$, hence if a firm keeps its capital level at $k_{0}$, it is unlikely that there will be any need to disinvest in the second period. This explains a put option value close to zero.

Consider now the put option value after firms choose $k_{1}$, both when in a boom (red thin solid line) and in a recession (blue thin dashed line). Low-productivity firms exercise some of their initial put option value by selling some capital. High-productivity firms, on the other hand, invest and thus "purchase" some put option value. Firms with intermediate productivity are in the inaction region and optimally choose to keep $k_{1}=k_{0}$. For these firms, the put option value at the end of the first period equals the initial put option value. In a recession, the put option value is lower than in a boom because of the equilibrium effect of the aggregate shock on the expected resale price discussed above. In equilibrium, firm's 
investment in the first period is endogenously more irreversible.

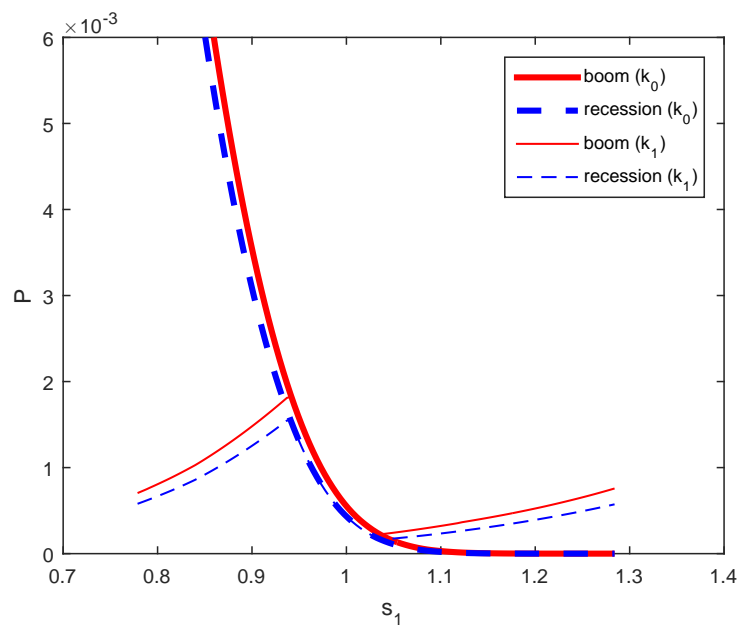

Figure 4: Put option values, before and after investment

\section{A DSGE model with endogenous irreversibility}

This section presents an infinite-horizon general equilibrium model that combines all the static and dynamic effects illustrated in the previous sections and includes risk aversion and endogenous labor supply, allowing for a quantitative evaluation of the mechanism.

\subsection{Households}

There is a representative household that consumes the output good, supplies labor and owns shares in all firms in the economy. Its preferences are described by the utility function

$$
\mathrm{E}_{0} \sum_{t=0}^{\infty}\left[\log \left(c_{t}\right)-\psi n_{t}\right]
$$

where $c_{t}$ is consumption and $n_{t}$ are hours worked.

The representative household's budget constraint is

$$
c_{t}=w_{t} n_{t}+\pi_{t}
$$


where $\pi_{t}$ are aggregate profits. ${ }^{12}$

The labor supply schedule is defined by the first order condition that equates the marginal rate of substitution between hours and consumption to the wage $w_{t}$

$$
\psi c_{t}=w_{t}
$$

\section{$5.2 \quad$ Firms}

Now, consider firms' optimization problem. In each period $t$, the productivity of firm $j$ is the product of an aggregate component $z_{t} \in\left\{z^{L}, z^{H}\right\}$ that follows a Markov chain with transition matrix $T_{z}$ and an idiosyncratic component $s_{j t} \in\left\{s^{L}, s^{H}\right\}$ with Markov transition matrix $T_{s}$. The firm produces a homogeneous output good with technology

$$
y_{j t}=z_{t} s_{j t} k_{j t}^{\alpha} n_{j t}^{\nu}
$$

with $\alpha+\nu<1$, and it chooses current labor demand and the future level of capital in order to maximize its value for the consumer, taking prices $q_{t}$ and $w_{t}$ as given. ${ }^{13}$ By assuming a flexible labor market with no adjustment costs, I can separate the labor demand choice from the investment decision in a very convenient way. I first describe the intratemporal labor decision and then derive the implied return on capital in order to formulate the intertemporal investment problem.

Labor demand equates the marginal product of labor to the wage rate:

$$
n_{j t}=\left(\frac{\nu z_{t} s_{j t} k_{j t}^{\alpha}}{w_{t}}\right)^{\frac{1}{1-\nu}}
$$

Using (16), it is easy to derive an expression for output net of the wage bill as a function of the two productivity shocks, current capital level and wage:

$$
y_{j t}-w_{t} n_{j t}=A\left(w_{t}\right) z_{t}^{\theta} s_{j t}^{\theta} k_{j t}^{\alpha \theta}
$$

where $A\left(w_{t}\right)=\left[\left(\frac{\nu}{w_{t}}\right)^{\frac{\nu}{1-\nu}}-w_{t}\left(\frac{\nu}{w_{t}}\right)^{\frac{1}{1-\nu}}\right]$, and $\theta=1 /(1-\nu)$. Firms use this transformation of the production function in order to evaluate the return on investment in physical capital.

\footnotetext{
${ }^{12}$ Alternatively, one could write this budget constraint including the household's choice of buying and selling shares in all firms. In equilibrium, its portfolio would have to coincide with the distribution of firms in the economy, and stock prices would be given by the firms' value functions below. The distinction between these two formulations is immaterial in terms of competitive equilibrium allocations and prices.

${ }^{13}$ Different from the simple models presented above, here I assume that capital is chosen one period in advance. This assumption makes the model more easily comparable to standard business-cycle models.
} 
The assumptions about the investment technology are analogous to those in the previous sections. The only difference is the presence of physical depreciation. For expanding firms, the capital accumulation equation is

$$
\begin{gathered}
k_{j t+1}=(1-\delta) k_{j t}+\widetilde{i}_{j t, \text { new }}+g\left(i_{j, \text { new }}, i_{j t, \text { used }}\right) \\
g\left(i_{j t, \text { new }}, i_{j t, \text { used }}\right)=\left[\eta^{\frac{1}{\epsilon}}\left(i_{j t, \text { new }}\right)^{\frac{\epsilon-1}{\epsilon}}+(1-\eta)^{\frac{1}{\epsilon}}\left(i_{j t, \text { used }}\right)^{\frac{\epsilon-1}{\epsilon}}\right]^{\frac{\epsilon}{\epsilon-1}}
\end{gathered}
$$

where $\widetilde{i}_{j t, n e w}$ and $i_{j t, n e w}$ are new investment goods and $i_{j, \text { used }}$ is used capital. Downsizing firms sell used capital $d_{j t}$.

$$
k_{j t+1}=(1-\delta) k_{j t}-d_{j t}
$$

The price index of new and used investment is

$$
Q_{t}=\left[\eta+(1-\eta)\left(q_{t}+\gamma\right)^{1-\epsilon}\right]^{\frac{1}{1-\epsilon}}
$$

I focus on the region of the parameter space where used capital (plus reallocation cost $\gamma$ ) is strictly cheaper than new capital; hence, $\widetilde{i}_{j t, n e w}=0$ for all firms (a suitable upper bound on the support of the aggregate productivity shock guarantees this).

Let $m$ be the distribution of firms over the individual capital level and idiosyncratic productivity. Both the price of used capital and the wage will depend on it, so this distribution is now a state variable with its own law of motion.

$$
m_{t+1}=\Gamma\left(m_{t}, z_{t}\right)
$$

I can now describe a recursive formulation of the firm's problem, with state vector $(k, s, z, m)$. After observing the state, each firm decides whether to invest or disinvest and by how much. The value of an investing firm is

$$
V^{i}(k, s, z, m)=\max _{k^{\prime} \geq(1-\delta) k} A(w) z^{\theta} s^{\theta} k^{\alpha \theta}-Q\left[k^{\prime}-(1-\delta) k\right]+\beta \mathrm{E}\left\{\frac{c}{c^{\prime}} V\left(k^{\prime}, s^{\prime}, z^{\prime}, m^{\prime}\right) \mid s, z\right\}
$$

and the value of a disinvesting firm is

$$
V^{d}(k, s, z, m)=\max _{k^{\prime} \leq(1-\delta) k} A(w) z^{\theta} s^{\theta} k^{\alpha \theta}-q\left[k^{\prime}-(1-\delta) k\right]+\beta \mathrm{E}\left\{\frac{c}{c^{\prime}} V\left(k^{\prime}, s^{\prime}, z^{\prime}, m^{\prime}\right) \mid s, z\right\}
$$

At the beginning of each period, the discrete choice between investment and disinvestment gives $V(k, s, z, m)=\max \left\{V^{i}(k, s, z, m), V^{d}(k, s, z, m)\right\}$. Note that these Bellman equations implicitly define the value of the firm as the present discounted value of profits (i.e., output net of the wage bill and investment expenditure), evaluated using the representative household's stochastic discount factor. 


\subsection{General Equilibrium}

Market clearing in the used capital market is imposed in an analogous way to the simpler models in the previous sections. Investing firms demand new capital and used capital by solving a standard CES expenditure minimization problem, and market clearing implies that total investment in used capital equals total disinvestment.

I can now define a recursive competitive equilibrium.

Definition 1. A recursive competitive equilibrium is defined as a set of functions $m, \Gamma, w$, $q, Q, \pi, C, N, V^{i}, V^{d}, V, n, k^{\prime}, i, i_{n e w}, i_{\text {used }}, d$ that solve the household's and firms' optimization problems and clear markets for the output good, labor and used capital:

- Consumption $C(z, m)$ and labor supply $N(z, m)$ solve the consumer's problem of maximizing (12) subject to (13)

- Firms' labor demand $n(k, s, z, m)$ satisfies equation (16)

- The value functions $V^{i}, V^{d}$ and $V$ satisfy the functional equations (23), (24) and $V(k, s, z, m)=\max \left\{V^{i}(k, s, z, m), V^{d}(k, s, z, m)\right\}$

- For investing firms - i.e. firms such that $V^{i}(k, s, z, m) \geq V^{d}(k, s, z, m)$ - the policy function $k^{\prime}(k, s, z, m)$ solves (23); investment is $i(k, s, z, m)=k^{\prime}(k, s, z, m)-(1-\delta) k$ and is allocated to new and used investment goods according to the CES expenditure minimization first order condition:

$$
\frac{i_{\text {used }}(k, s, z, m)}{i_{\text {new }}(k, s, z, m)}=\frac{1-\eta}{\eta}(q(z, m)+\gamma)^{-\epsilon}
$$

- For disinvesting firms - i.e. $V^{i}(k, s, z, m)<V^{d}(k, s, z, m)$ - the policy function $k^{\prime}(k, s, z, m)$ solves (24), and disinvestment is $d(k, s, z, m)=(1-\delta) k-k^{\prime}(k, s, z, m)$

- Aggregate profits are given by $\pi(z, m)=z \int s k^{\alpha} n^{\nu} d m(k, s)-w(z, m) N(z, m)$

$$
-Q(z, m) \int i(k, s, z, m) d m(k, s)+q \int d(k, s, z, m) d m(k, s)
$$

- The market for the output good clears:

$$
\begin{gathered}
C(z, m)=z \int s k^{\alpha} n^{\nu} d m(k, s)-Q(z, m) \int i(k, s, z, m) d m(k, s)+ \\
q \int d(k, s, z, m) d m(k, s)
\end{gathered}
$$


- The labor market clears: $N(z, m)=\int n(k, s, z, m) d m(k, s)$

- The market for used capital clears:

$$
\int d(k, s, z, m) d m(k, s)=\int i_{\text {used }}(k, s, z, m) d m(k, s)
$$

- The price functions $q(z, m)$ and $Q(z, m)$ satisfy equation (21)

- The transition function $\Gamma$ defines the evolution of the distribution of firms $m$ according to the policy function $k^{\prime}$ and the Markov transition matrices $T_{s}$ and $T_{z}$.

\subsection{Calibration}

Table 2 reports the choice of parameter values. When possible, these choices reflect the intention to be close to previous work on firm heterogeneity and investment for comparison purposes (in particular, Khan and Thomas, 2013). A period coincides with a year: this choice is motivated by the fact that the data on both capital reallocation and micro-level investment are yearly.

Parameters $\beta, \psi$ and $\delta$ correspond to a yearly interest rate of four percent, hours worked equal to .33 and an investment/capital ratio of $6.5 \%$. The capital share $\alpha$ is then set to match a capital/output ratio around 2.5. The labor share $\nu$ is $60 \%$, as in the US postwar data.

Both aggregate and idiosyncratic shocks are initially parametrized as $\operatorname{AR}(1)$ processes in logs with autocorrelations $\rho_{z}$ and $\rho_{s}$ and standard deviations of innovations $\sigma_{i n n, z}$ and $\sigma_{i n n, s}$. Then, they are discretized following the Rouwenhorst method with two values for each shock.

In particular, aggregate productivity $z_{t}$ is parametrized as in Khan and Thomas (2013), who estimate a process for the Solow residual in the US data. This gives a standard deviation of innovations of .014 and an autocorrelation coefficient of .909.

The standard deviation of the process for the idiosyncratic shock $s$ is calibrated to match the standard deviation of the distribution of investment ratios computed by Cooper and Haltiwanger (2006), which is .33. The autocorrelation of the process is parametrized as in Khan and Thomas (2013) to be equal to .65. This implies a standard deviation of innovations of $.084 . .^{14}$

The investment technology is defined by two parameters: $\eta$ and $\epsilon$. The first parameter is calibrated to match the steady-state ratio of capital reallocation to investment (approximately 30\%). The elasticity of substitution between new and used investment goods $\epsilon$ is a key parameter of the model. Edgerton (2011) estimates this elasticity using data from construction equipment, aircraft and farming equipment and exploiting a tax-credit reform

\footnotetext{
${ }^{14}$ The discretization with a two-state Markov chain implies that the average autocorrelation of investment rates and the frequency of large adjustments (lumpiness) cannot be matched at the same time as the standard deviation of the investment rate, different from Khan and Thomas (2013).
} 
that affects only new investment. He finds values in a range between 1 and 10 . I set $\epsilon=5$ as my benchmark value. In addition to being an intermediate value in this range of estimates, it allows me to match the standard deviation of the ratio between used and new capital expenditure from ACES data (Figure 14), which is around 1\%. I show the results for different values of $\epsilon$ (1 and 10) in the robustness section. Note that the baseline choice implies that the relative price of used capital will move less in the model than in the data shown in the empirical section, so that this parametrization is quite conservative. Finally, I set $\gamma=.01$, which implies a steady-state resale price of .95, close to the constant resale price in Khan and Thomas (2013). Hence, in the stationary equilibrium without aggregate shocks, the baseline economy is a very close match with a version of the Khan and Thomas (2013) economy without financial frictions.

\begin{tabular}{|c|c|c|c|c|c|c|c|c|c|c|c|}
\hline$\beta$ & $\delta$ & $\psi$ & $\alpha$ & $\nu$ & $\sigma_{i n n, z}$ & $\rho_{z}$ & $\sigma_{i n n, s}$ & $\rho_{s}$ & $\eta$ & $\epsilon$ & $\gamma$ \\
\hline .96 & .065 & 2.15 & .27 & .6 & .014 & .909 & .084 & .65 & .7 & 5 & .01 \\
\hline
\end{tabular}

Table 2: Parameter values

\section{Results}

This section presents the numerical results from the full model, starting with firm dynamics in a stationary equilibrium and then moving to the model's business-cycle properties.

\subsection{Stationary equilibrium: no aggregate uncertainty}

This subsection describes the equilibrium of the model when there is no aggregate uncertainty and $z$ is always equal to its mean. Consider, first, the investment policy function obtained by solving firms' optimization problem. As in the simpler models presented in the previous sections, the wedge between the price of investment goods $Q_{t}$ and the resale price $q_{t}$ generates inaction areas, where firms optimally let their capital depreciate without taking any action. As $q_{t}<Q_{t}$, the capital level that solves (23) without the inequality constraint of positive investment - call it $k^{i}(k, s, z, m)$ - is strictly less than the capital level that solves (24) without the inequality constraint of positive disinvestment - call it $k^{d}(k, s, z, m)$. It follows that the policy function for future capital will be:

$$
k^{\prime}(k, s, z, m)= \begin{cases}k^{i}(k, s, z, m), & k \leq k^{i}(k, s, z, m) /(1-\delta) \\ (1-\delta) k, & k^{i}(k, s, z, m) /(1-\delta)<k \leq k^{d}(k, s, z, m) /(1-\delta) \\ k^{d}(k, s, z, m), & k>k^{d}(k, s, z, m) /(1-\delta) .\end{cases}
$$

Figure 5 illustrates the policy function for future capital for firms with low productivity 


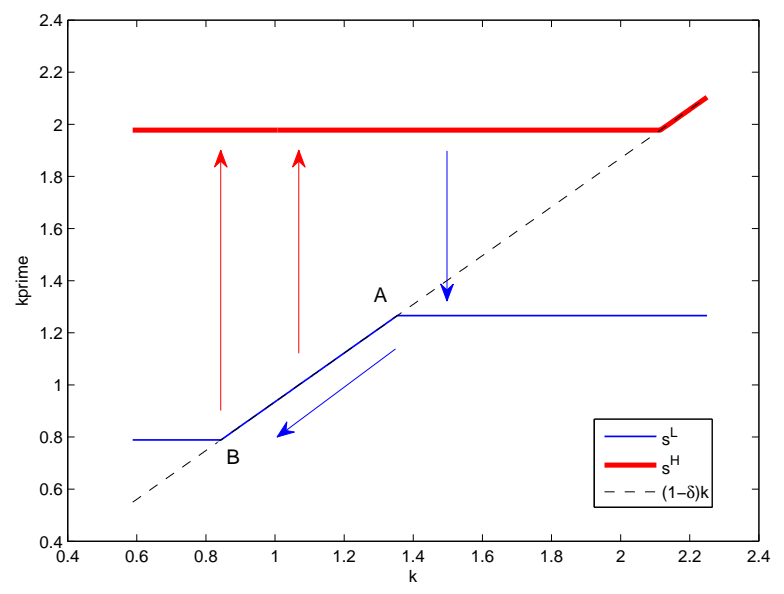

Figure 5: Policy function for future capital level

(thin blue line) and high productivity (thick red line) under the parametrization reported in Table 2. The variable on the x-axis is the current capital level, while on the $\mathrm{y}$-axis, I plot next period capital. In a world without resale frictions, this picture would consist of only two horizontal lines, one at a higher level for $s^{H}$ and one at a lower level for $s^{L}$, and firms would jump from one level to another, depending on the current realization of $s$ and regardless of their size $k$, given that there would be no adjustment costs. However, partial irreversibility induces disinvesting firms not to sell the whole amount of capital needed to jump to the bottom part of the blue line (point B). This is because they expect to need to reinvest in the future if they receive a positive idiosyncratic shock in the following period, and they would clearly incur a loss due to the fact they would repurchase capital at a higher price than the one obtained for their disinvestment. In other words, the wedge between the price paid for investment and the price received for disinvestment creates an option value from waiting and, hence, an inaction region where firms optimally wait and let their capital depreciate. The inaction region for low-productivity firms is the upward-sloping part of the thin blue line, between points $\mathrm{A}$ and $\mathrm{B}$, which coincides with the depreciation line (dashed black line). Note that there also is an inaction region for high-productivity firms (top right in the figure), but it turns out that firms never invest enough to enter this area in equilibrium.

Firm-level dynamics in the stationary equilibrium are as follows. As soon as firms get a high idiosyncratic shock, they jump to the horizontal part of the thick red line and stay there as long as they have high productivity. As soon as they get a bad shock that brings them to $s^{L}$, they sell part of their capital and jump down to the thin blue line, close to point A. Then, as long as they have productivity $s^{L}$, they move left along this line until they reach point B, where they stay until the next positive shock. Therefore, in the market for used capital, 
supply comes from the firms that have a high level of capital and get a negative idiosyncratic shock, whereas demand comes from firms of all sizes that obtain a positive shock and from the smallest firms with low productivity that invest to keep their size constant.

These firm-level dynamics give rise to the stationary distribution plotted in Figure 6, where the $\mathrm{x}$-axis is again $k$ and the $\mathrm{y}$-axis is the mass of firms $m$. The thick red line with high mass on the right-hand side of the picture represents firms with productivity $s^{H}$. Moving towards the left, the thin blue lines with crosses represent the masses of firms with productivity $s^{L}$. Gradually, the mass decreases as some of the firms of those sizes receive a positive shock and only the remaining fraction let their capital depreciate for one more period. At the left side of the figure, there is a mass of low productivity firms that simply rebuy their depreciated capital and remain small until they get a positive idiosyncratic shock (point B).

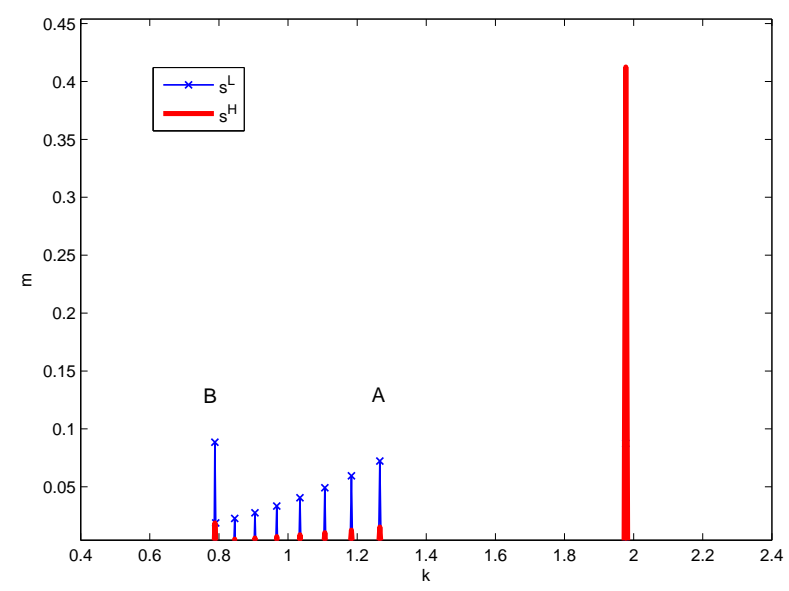

Figure 6: Stationary distribution of firms

\subsection{Business cycles and capital reallocation}

I now describe the properties of the economy when it is hit by aggregate productivity shocks. Table 3 shows standard business-cycle statistics, as well as statistics for the resale price of capital and the reallocation series, taken from a simulation of the model economy. The first row presents the unconditional mean of the variables of interest. To construct the second and third rows, I HP-filter the data with a smoothing parameter of 6.25 and then compute relative standard deviations and correlations with output. ${ }^{15}$ The standard deviation of output is in

\footnotetext{
${ }^{15}$ Khan and Thomas (2013) use a smoothing parameter of 100 . In the interest of a comparison with their results, I recompute these two tables with a smoothing parameter of 100 in Appendix D.
} 
parentheses. It is instructive to compare these business-cycle statistics with those obtained in an economy with constant resale price (Table 4), which closely resembles a version of the Khan and Thomas (2013) economy without financial frictions.

As far as standard business-cycle variables are concerned, endogenous irreversibility reduces output and employment volatility slightly and investment volatility quite significantly (this result is discussed in more detail in a later subsection). By comparing the last columns of Tables 3 and 4, it can be seen that going from a constant $q$ to a market-clearing resale price of capital, reallocation turns from being highly countercyclical (the puzzle) to being highly procyclical and approximately three times as volatile as output. In the data, reallocation is ten times as volatile as output and their correlation is .7. Hence, the model can explain about $30 \%$ of the cyclical volatility of the Eisfeldt and Rampini (2006) series and more than half of the volatility of the Sales of Properties, Plants and Equipment component of reallocation.

In Appendix D, I show that robustness exercises with respect to the elasticity of substitution $\epsilon$ lead to similar results. The volatility of the reallocation series is decreasing in $\epsilon$, as expected: the lower this elasticity, the more specific the used capital, and, hence, the stronger the effects of aggregate shocks on reallocation. The procyclicality of reallocation is robust to different values of this elasticity.

\begin{tabular}{|c|c|c|c|c|c|c|c|}
\hline Statistic & $\mathrm{Y}$ & $\mathrm{C}$ & $\mathrm{I}$ & $\mathrm{K}$ & $\mathrm{N}$ & $\mathrm{q}$ & reall \\
\hline \hline mean & .591 & .492 & .098 & 1.501 & .335 & .952 & .049 \\
\hline$\sigma(.) / \sigma(Y)$ & $(1.31)$ & .479 & 3.964 & .253 & .551 & .193 & $\mathbf{3 . 2 0 6}$ \\
\hline $\operatorname{corr}(., \mathrm{Y})$ & 1 & .930 & .963 & -.317 & .986 & .972 & $\mathbf{. 9 6 7}$ \\
\hline
\end{tabular}

Table 3: Business-cycle statistics: baseline model

\begin{tabular}{|c|c|c|c|c|c|c|c|}
\hline Statistic & $\mathrm{Y}$ & $\mathrm{C}$ & $\mathrm{I}$ & $\mathrm{K}$ & $\mathrm{N}$ & $\mathrm{q}$ & reall \\
\hline \hline mean & .590 & .492 & .098 & 1.502 & .335 & .951 & .0486 \\
\hline$\sigma(.) / \sigma(Y)$ & $(1.38)$ & .396 & 4.830 & .290 & .612 & 0 & $\mathbf{1 . 2 1 7}$ \\
\hline $\operatorname{corr}(., \mathrm{Y})$ & 1 & .833 & .951 & -.287 & .983 & 0 & $\mathbf{- . 8 3 4}$ \\
\hline
\end{tabular}

Table 4: Business-cycle statistics: constant $q$

A limitation of the model is that the volatility of the resale price $q_{t}$ is small compared to the volatilities implied by the sectoral data presented in Section 2. However, this suggests that even a small amount of volatility and procyclicality in this price can go a long way in explaining the empirical patterns of capital reallocation.

In Figures 7 and 8, I show the (unfiltered) paths of the resale price and the reallocation series when the economy goes from a long series of high realizations of the aggregate produc- 
tivity shock to a long series of low realizations. It can be clearly seen that in the baseline model, the initial fall in the resale price induces a large decrease in capital reallocation. This is in contrast to a model with constant resale price (black line with crosses), where reallocation actually increases in the first two years of the recession and then falls gradually as the capital stock and the size of the whole economy decrease. Figure 7 highlights the role of equilibrium real options in the mechanism. Notice that the price of used capital falls at the beginning of the recession, when there is a large stock of installed capital that firms try to dispose of. Subsequently, as some of this capital gets reallocated or depreciates, the price of used capital recovers, even though the economy is still in the low aggregate productivity state. This illustrates that when the aggregate shock initially hits, firms with rational expectations understand that capital has a high option value given by a higher future resale price, and waiting to downsize (or, equivalently, downsizing by less) is optimal.

Figure 9 illustrates the effect of endogenous irreversibility on the dispersion of the marginal product of capital, as measured by the average marginal product for high productivity $\left(s^{H}\right)$ firms and that for low productivity ones $\left(s^{L}\right)$. Consistent with a growing body of empirical evidence (Bloom et al., 2012), the model implies that returns are more dispersed in recessions than in booms. This fact is a manifestation of the lack of reallocation, because large unproductive firms downsize less than they would in a model with constant irreversibility, which prevents an equalization of marginal returns. The previous literature has either taken the countercylicality of dispersion of returns as fully exogenous (e.g., Bloom et al., 2012) or explained it as a consequence of financial frictions (e.g., Chen and Song, 2013, Ai, Li and Yang, 2015). This paper suggests a different explanation based on partial capital specificity, which bears important consequences for policy. If one interprets the high levels of observed dispersion of returns from capital as being due to a worsening of credit frictions, it is possible that a credit expansion or unconventional monetary policy could facilitate reallocation and strengthen the recovery. If, instead, the high dispersion is efficient and due to capital specificity and equilibrium irreversibility, then no policy intervention is in order and credit expansions are not relevant.

The dynamics of the distribution of firms over the business cycle are illustrated in Figure 10. It can be seen that the distribution becomes more compressed when the economy moves from a boom to a recession: large unproductive firms downsize by less than they do in booms (compare points A and A'), while highly productive units expand by less. Jointly, these facts explain the decline in reallocation and the increase in the dispersion of returns.

This mechanism also generates a procyclical dispersion of investment rates. This result is qualitatively consistent with the empirical evidence presented by Bachmann and Bayer (2014), in spite of the fact that the dispersion of idiosyncratic shock is constant in my model, different from their model, which features uncertainty shocks. The correlation between HPfiltered output and the standard deviation of investment rates is .87 in the model and .45 in the German data used by Bachmann and Bayer (2014).

In Appendix E I show that the procyclicality of reallocation is robust to a different source 
of business-cycle fluctuations, namely investment-specific technology shocks, as studied by Greenwood et al. (2000). I modify the model to include a relative price of new investment (relative to consumption) and show that when an aggregate shock increases this price inducing a recession, both new investment and reallocation of used capital decline.

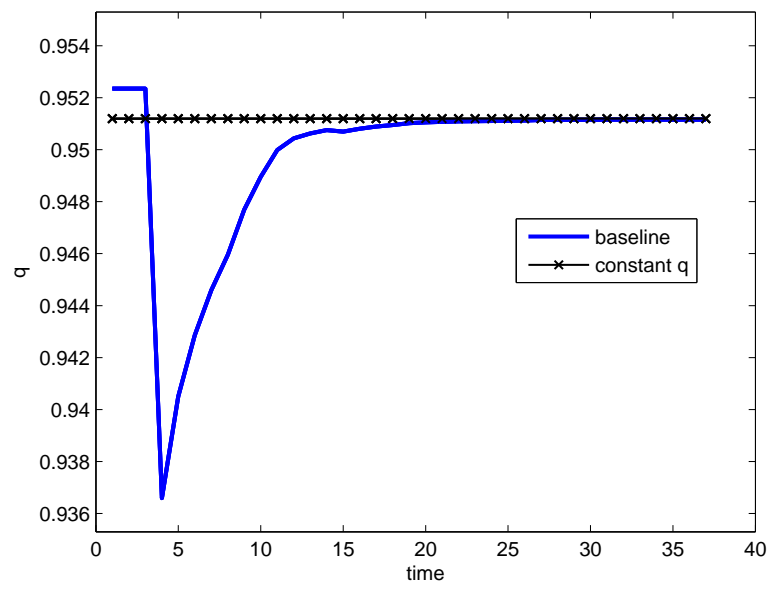

Figure 7: Price of used capital

Transition from long sequence $z_{t}=z^{H}$ to long sequence $z_{t}=z^{L}$. Response of the price of used capital. Comparison between the baseline model and a model with constant resale price. Unfiltered simulated data.

\subsection{Amplification of aggregate TFP}

The procyclicality of reallocation generates endogenous movements in aggregate TFP, amplifying the exogenous aggregate productivity shock. Measured TFP - call it $Z_{t}$ - is the Solow residual that an econometrician would compute by assuming an aggregate production function $Y_{t}=Z_{t} K_{t}^{\alpha} N_{t}^{\nu}$. A large part of the variation in this variable is due to the exogenous component $z_{t}$, while the rest is due to how capital and labor are allocated across the heterogeneous productive units in the economy. In the model, this second component, $T F P_{\text {end }} \equiv \log \left(Z_{t}\right)-\log \left(z_{t}\right)$, is of second order when compared to the exogenous component, so the absolute importance of the allocative component of TFP should not be overemphasized.

However, as Table 5 shows, this component is magnified by endogenous irreversibility. Both the ratio between its volatility and the volatility of the shock $\left(\sigma_{T F P e n d} / \sigma_{z}\right)$ and the ratio between its volatility and that of output $\left(\sigma_{T F P e n d} / \sigma_{Y}\right)$ increase by more than four times when going from constant to endogenous irreversibility. Note that this should be seen as a lower bound for the importance of capital reallocation for aggregate TFP, because the model generates less volatility in both $q_{t}$ and the reallocation series than we observe in the data. 


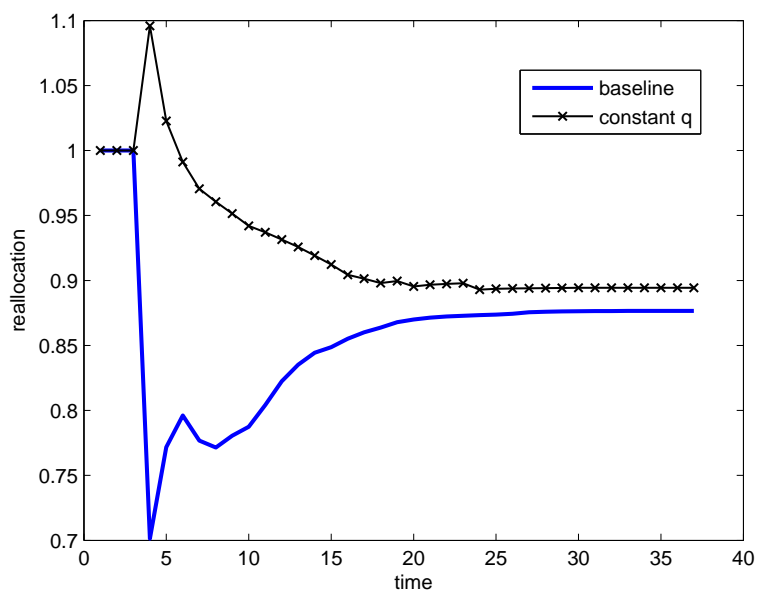

Figure 8: Capital reallocation

Transition from long sequence $z_{t}=z^{H}$ to long sequence $z_{t}=z^{L}$. Response of capital reallocation. Comparison between the baseline model and a model with constant resale price. Unfiltered simulated data.

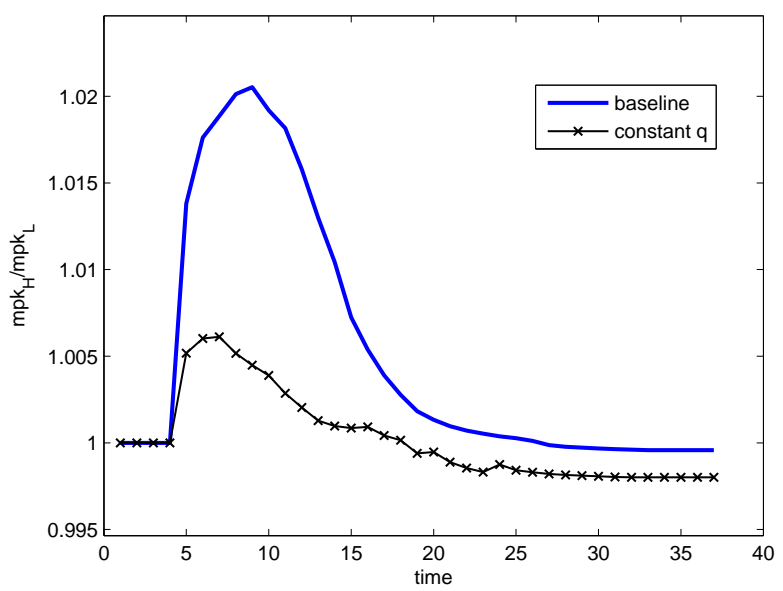

Figure 9: Dispersion of returns

Transition from long sequence $z_{t}=z^{H}$ to long sequence $z_{t}=z^{L}$. Response of the ratio between the average marginal product of high-productivity firms $\left(s^{H}\right)$ and that of low-productivity firms $\left(s^{L}\right)$. Comparison between the baseline model and a model with constant resale price. Unfiltered simulated data. 

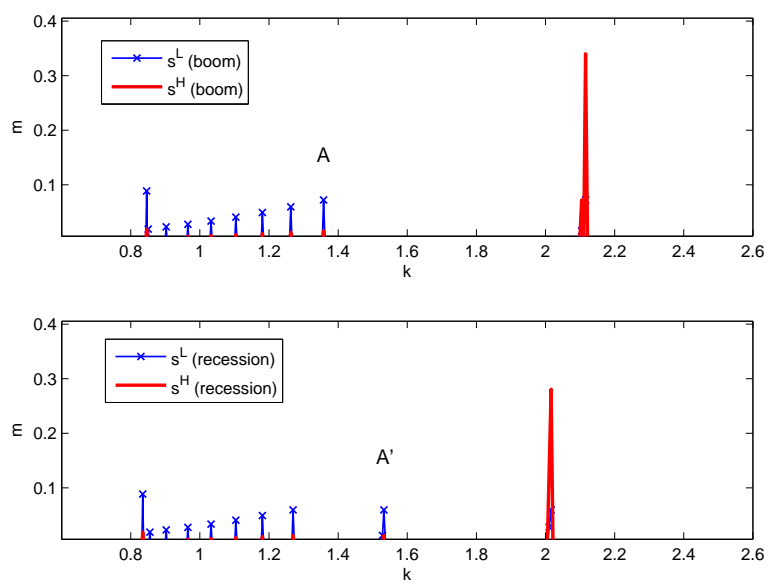

Figure 10: Distribution dynamics

Transition from long sequence $z_{t}=z^{H}$ to long sequence $z_{t}=z^{L}$. Cross-sectional distribution of firms before and after the shock.

The amplification mechanism for TFP works as follows: during recessions, reallocation decreases and firms with idiosyncratic productivity $s^{L}$ are, in a sense, "too large" which implies not only that capital is less productively used, but also that employment is "too high" in these relatively less productive firms, as labor demand is an increasing function of a firm's capital stock. Hence, the allocation of inputs gets further away from the allocation that would arise in a model where investment and disinvestment are fully flexible. However, the allocation is always efficient, in the sense that it would coincide with the choice of a planner that faced the same technological constraints.

Furthermore, to see how this mechanism is propagated over time, observe, again, the policy functions illustrated in Figure 5. When large firms are hit by a negative idiosyncratic shock, they sell part of their capital once and then let their capital depreciate until they become highly productive again. This means that if they sell a small amount of capital in the first period, they will remain "too large" (relative to a model with constant $q$ ) for several periods, until they get a positive idiosyncratic shock again. Thus, the negative effects of lower reallocation on aggregate productivity in recessions are propagated over time through these movements in the distribution of firms. This implication of the model seems consistent with the patterns observed in the current slow recovery of productivity in the UK, which Broadbent (2012) attributes precisely to insufficient capital reallocation.

It is worth emphasizing that the degree of amplification of TFP in the model is increasing in the dispersion of idiosyncratic productivity across firms: the more dispersed productivity is, the larger the benefits from reallocation will be. Hence, the procyclicality of capital reallo- 
cation induces larger movements in aggregate productivity when the variance of $s_{t}$ is higher. For instance, doubling the unconditional variance of $s_{t}$ leads to $\sigma_{T F P e n d} / \sigma_{z}=0.0278$ and $\sigma_{T F P e n d} / \sigma_{Y}=0.0178$. In this paper, the volatility of idiosyncratic productivity is calibrated to match micro-level investment data following the methodology of Khan and Thomas (2008, 2013). However, in the literature there is no unanimous agreement on this parameter value and, in general, on the procedure to parametrize the idiosyncratic productivity process. For example, Bloom et al. (2012) estimate time-varying volatilities of firm-level productivity and get values for volatility of up to $12 \%$ quarterly in high-uncertainty periods. This suggests that the amplification of aggregate productivity delivered by the present paper is a lower bound for the empirical effect of procyclical capital reallocation on TFP.

\begin{tabular}{|c|c|c|}
\hline Model & $\sigma_{\text {TFPend }} / \sigma_{z}$ & $\sigma_{\text {TFPend }} / \sigma_{Y}$ \\
\hline \hline Constant $q$ & 0.003 & 0.002 \\
\hline Baseline & 0.013 & 0.009 \\
\hline
\end{tabular}

Table 5: Amplification of endogenous TFP

\subsection{Endogenous irreversibility and aggregate investment}

The previous literature on investment irreversibility has debated whether the observed smoothness of the aggregate investment series can be attributed to irreversibility at the micro level. Bertola and Caballero (1994) affirm this point in a partial equilibrium model and suggest that the fear of not being able to disinvest may act as a smoothing device at the time of investing, making firms more cautious in their investment decisions and generating inaction regions. However, Veracierto (2002) introduces constant partial irreversibility in a general equilibrium model with heterogeneous plants and shows that the properties of aggregate investment are unchanged when moving from totally flexible to totally irreversible investment. ${ }^{16}$ The reason is that consumption smoothing makes the interest rate adjust in such a way that aggregate investment has the same desired properties for the representative agent. Furthermore, aggregate shocks shift the inaction region without affecting its size over time.

The present model reaffirms the original conjecture of Bertola and Caballero (1994) by making irreversibility an equilibrium outcome that moves over the business cycle. Investment becomes more irreversible in recessions, when unproductive firms would like to disinvest by more. This makes investment riskier for firms, thus making them more cautious when they invest. Furthermore, the endogenous prices for investment goods act in the direction of smoothing the investment decisions even more: in a recession, when investment falls, used

\footnotetext{
${ }^{16}$ Of course, the properties of micro-level investment decisions are very different depending on the level of irreversibility.
} 
capital is cheaper, which implies that total investment becomes cheaper ( $Q_{t}$ falls), hence dampening the fall in aggregate investment. The opposite happens in booms, when firms want to invest more, but $Q_{t}$ increases. This shows that equilibrium in the market for used capital affects the decision to create new capital, which in the aggregate we measure as aggregate investment. Comparing Tables 3 and 4 again, we see that the volatility of aggregate investment relative to output falls from 4.8 to just less than 4 .

Following the previous literature on micro lumpiness and aggregate investment (e.g., Khan and Thomas, 2008), in Appendix D I also report the volatility and autocorrelation of the unfiltered investment/capital ratio. Table 12 compares the baseline model with the model with constant $q$. With endogenous irreversibility, the investment/capital ratio is more persistent, and its innovations are less volatile than in the comparison model. The empirical autocorrelation of aggregate investment is an intermediate value between the values obtained in the two models, suggesting that the mechanism in this paper smooths the aggregate investment rate (slightly) more than needed to exactly match the data.

\section{Conclusion}

This paper shows that the procyclicality of capital reallocation can be rationalized in a model in which the resale price of capital is endogenous. According to the new data presented, this price is procyclical, making it harder to reverse past investment decisions during recessions. The model generates this result as an equilibrium outcome by assuming that new and used investment goods are imperfect substitutes because of partial firm-level capital specificity. Hence, in a recession, a higher supply of used capital and lower demand lead to a fall in the price, inducing both static and dynamic effects on investment and reallocation via the equilibrium response of real-option values. This mechanism induces endogenous movements in aggregate TFP because during expansions, when the resale price of capital increases, the allocation of capital and labor is closer to the allocation that would arise in a flexible model. Vice versa, in downturns more capital is operated by unproductive firms.

Endogenous irreversibility is a plausible mechanism behind a smooth aggregate investment series. In this sense, the paper provides an explicit microfoundation for what, in the aggregate, resembles a convex capital adjustment cost. Furthermore, the model generates a countercyclical dispersion of returns, consistent with a growing literature on firm-level uncertainty. Previous work has connected a high dispersion of returns in recessions with the malfunctioning of credit markets, hence providing one rationale for expansionary credit policies. This paper suggests that part of this increased dispersion, which was emphasized in both academic and policy work during the Great Recession, is not necessarily related to credit conditions and may be attributable, instead, to partial capital specificity.

While this model assumes frictionless financial markets, financing constraints clearly may

play an important role in shaping investment and reallocation dynamics. Introducing a 
collateral constraint that ties the borrowing capacity to the resale value of a firm's capital is likely to amplify the response of the economy to aggregate productivity shocks. The value of a firm's collateral depends on the resale price of its assets. Therefore, an extension of the present model with collateral constraints could potentially generate an endogenous tightening of collateral constraints after a negative TFP shock, reconciling both the cyclicality of reallocation and that of credit availability in a model with production heterogeneity.

Furthermore, US plant-level data suggest that while entry is strongly procyclical, exit is almost acyclical (Lee and Mukoyama, 2015). This evidence on exit is a puzzle for models with productivity shocks, where the exit decision is driven by a fixed cost of production denominated in units of the output good. In such models, after a bad aggregate TFP shock, more firms optimally decide to liquidate their capital and exit. Endogenous irreversibility seems to be a promising explanation for this puzzle. In a recession, on the one hand, the value of staying in business falls, and more firms would like to exit, but on the other hand the value of exit also falls, as it depends of the resale price of capital, and, overall, the incentive to liquidate is dampened.

Finally, this paper provides a natural framework to analyze movements in the utilization rate of capital both in the aggregate and at the micro level. A large firm hit by a negative profitability shock can choose whether to reallocate its assets or to keep them idle for some time, hoping for an improvement in business conditions. The previous literature on heterogeneous firms and capacity utilization has imposed restrictions on the possibility of selling assets after the realization of idiosyncratic productivity shocks in order to justify unproductive firms' choice to keep some idle capital (e.g., Hansen and Prescott, 2005; Sustek, 2011). In the context of a model with endogenous irreversibility, no such assumptions are necessary. Depending on aggregate conditions, the resale price of capital may be high enough to induce unproductive firms to reallocate capital or low enough to make it optimal for them to keep some capital idle. A quantitative exploration of an equilibrium model with endogenous irreversibility and capacity utilization is left for future work. 


\section{References}

[1] Abel, A.B., A.K. Dixit, J.C. Eberly, R.S. Pindyck (1996), Options, the Value of Capital, Investment, The Quarterly Journal of Economics, 111 (3), 753-777.

[2] Ai, H., K. Li, F. Yang (2015), Financial Intermediation and Capital Misallocation, Working Paper

[3] Ai, H., D. Kiku (2013), Growth to Value: Option Exercise and the Cross-Section of Equity Returns, Journal of Financial Economics, 107(2), 325-349.

[4] Asker, J., A. Collard-Wexler, J. De Loecker (2014), Dynamic Inputs and Resource (Mis)Allocation, Journal of Political Economy, 122(5), 1013-1063.

[5] Bachmann, R., C. Bayer (2014), Investment Dispersion and the Business Cycle, American Economic Review, 104(4), 1392-1416.

[6] Backus, D.K., P.J. Kehoe, F.E. Kydland (1994), Dynamics of the Trade Balance and the Terms of Trade: The J-Curve?, American Economic Review, 84(1), 84-103.

[7] Barnett, A., B. Broadbent, A. Chiu, J. Franklin, H. Miller (2014), Impaired Capital Reallocation and Productivity, National Institute Economic Review, 228:R35, NIESR

[8] Bertola, G., R. J. Caballero (1994), Irreversibility and Aggregate Investment, Review of Economic Studies, 61(2), 223-246.

[9] Bloom, N. (2009), The Impact of Uncertainty Shocks, Econometrica, 77(3), 623-685.

[10] Bloom, N., M. Floetotto, N. Jaimovich, I. Saporta-Eksten, S.J. Terry (2012), Really Uncertain Business Cycles, NBER Working Paper, No. w18245

[11] Broadbent, B. (2012), Productivity and the Allocation of Resources, Speech given at Durham Business School, 12th September

[12] Caunedo, J. (2015), Industry Dynamics, Investment and Business Cycles, Working Paper

[13] Chen, K., Z. Song (2013), Financial Frictions on Capital Allocation: A Transmission Mechanism of TFP Fluctuations, Journal of Monetary Economics, 60(6), 683-703.

[14] Cooper, R.W., J.C. Haltiwanger (2006), On the Nature of Capital Adjustment Costs, Review of Economic Studies, 73(3), 611-633.

[15] Cooper, R.W., I. Schott (2013), Capital Reallocation and Aggregate Productivity NBER Working Paper No. 19715 
[16] Cui, W. (2014), Delayed Capital Reallocation, Working Paper

[17] Cui, W., S. Radde (2015), Search-Based Endogenous Illiquidity, Working Paper

[18] den Haan, W. (2010), Assessing the Accuracy of the Aggregate Law of Motion in Models with Heterogeneous Agents, Journal of Economic Dynamics and Control, 34(1), 79-99.

[19] Dixit, A.K., R.S. Pindyck (1994), Investment under Uncertainty, Princeton University Press

[20] Edgerton, J. (2011), The Effects of Taxation on Business Investment: New Evidence from Used Equipment, Working Paper

[21] Eisfeldt, A.L. (2004), Endogenous Liquidity in Asset Markets, Journal of Finance, 59(1), 1-30.

[22] Eisfeldt, A.L., Rampini, A.A. (2006), Capital Reallocation and Liquidity, Journal of Monetary Economics, 53(3), 369-399.

[23] Eisfeldt, A.L., Rampini, A.A. (2007), New or Used? Investment with Credit Constraints, Journal of Monetary Economics, 54(8), 2656-2681.

[24] Gavazza, A. (2011a), Leasing and Secondary Markets: Theory and Evidence from Commercial Aircraft, Journal of Political Economy, 119(2), 325-377.

[25] Gavazza, A. (2011b), The Role of Trading Frictions in Real Asset Markets, The American Economic Review, 101(4), 1106-1143.

[26] Gilchrist, S, J.W. Sim, E. Zagrasjek. (2014), Uncertainty, Financial Frictions, and Investment Dynamics, NBER Working Paper No. 20038

[27] Greenwood, J., Z. Hercowitz, P. Krusell (2000), The Role of Investment-specific Technological Change in the Business Cycle, European Economic Review, 44(1), 91-115.

[28] Hansen, G.D. (1985), Indivisible Labor and the Business Cycle, Journal of Monetary Economics, 16(3), 309-327.

[29] Hansen, G.D., E.C. Prescott (2005), Capacity Constraints, Asymmetries, and the Business Cycle, Review of Economic Dynamics, 8(4), 850-865.

[30] Hopenhayn, H.A. (1992), Entry, Exit, and Firm Dynamics in Long Run Equilibrium, Econometrica, 60(5), 1127-50.

[31] Jovanovic, B., P.L. Rousseau (2008), Mergers as Reallocation, The Review of Economics and Statistics, 90(4), 765-776. 
[32] Jovanovic, B., Y. Yatsenko (2012), Investment in Vintage Capital, Journal of Economic Theory, 147(2), 551-569.

[33] Khan, A., J.K. Thomas (2008), Idiosyncratic Shocks and the Role of Nonconvexities in Plant and Aggregate Investment Dynamics, Econometrica, 76(2), 395-436.

[34] Khan, A., J.K. Thomas (2013), Credit Shocks and Aggregate Fluctuations in an Economy with Production Heterogeneity, Journal of Political Economy, 121(6), 1055-1107.

[35] Krusell, P., A.A. Smith (1998), Income and Wealth Heterogeneity in the Macroeconomy, Journal of Political Economy, 106(5), 867-896.

[36] Krusell, P., A.A. Smith (2006), Quantitative Macroeconomic Models with Heterogeneous Agents, in Advances in Economics and Econometrics: Theory and Applications, Ninth World Congress

[37] Kurlat, P. (2013), Lemons Markets and the Transmission of Aggregate Shocks, American Economic Review, 103(4), 1463-89.

[38] Lee, Y., T. Mukoyama (2015), Entry and exit of manifacturing plants over the business cycle , European Economic Review, vol 77(C), 20-27.

[39] Li, S., T.M. Whited (2014), Capital Reallocation and Adverse Selection, Simon Business School Working Paper No. FR 14-16

[40] Ljungqvist, L., T. J. Sargent (2004) Recursive Macroeconomic Theory, 2nd Edition, The MIT Press,

[41] Maksimovic, V., G. Phillips (2001), The Market for Corporate Assets: Who Engages in Mergers and Asset Sales and are there Efficiency Gains? The Journal of Finance, 56(6), 2019-2065.

[42] Newey, W.K. and K.D. West (1987), A Simple, Positive Semi-definite, Heteroskedasticity and Autocorrelation Consistent Covariance Matrix, Econometrica, 55(3), 703-708.

[43] Osotimehin, S. (2013), Aggregate productivity and the allocation of resources over the business cycle, Working Paper, University of Virginia, Department of Economics.

[44] Ottonello, P. (2015), Capital Unemployment, Financial Shocks, and Investment Slumps, Working Paper

[45] Ramey, V.A., M.D. Shapiro (2001), Displaced Capital: A Study of Aerospace Plant Closings, Journal of Political Economy, 109(5), 958-992. 
[46] Ravn, M.O., H. Uhlig (2002), On Adjusting the Hodrick-Prescott Filter for the Frequency of Observations, The Review of Economics and Statistics, 84(2), 371-375.

[47] Rogerson, R. (1988), Indivisible Labor, Lotteries and Equilibrium, Journal of Monetary Economics, 21(1), 3-16.

[48] Sargent, T.J. (1980), Tobin's q and the Rate of Investment in General Equilibrium, Carnegie-Rochester Conference Series on Public Policy, 12(1), 107-154.

[49] Shleifer, A., R.W. Vishny (2012), Liquidation Values and Debt Capacity: A Market Equilibrium Approach. The Journal of Finance, 47(4), 1343-1366.

[50] Sustek, R. (2011), Plant-level Nonconvex Output Adjustment and Aggregate Fluctuations, Journal of Monetary Economics, 58(4), 400-414.

[51] Veracierto, M. L. (2002), Plant-level Irreversible Investment and Equilibrium Business Cycles, American Economic Review, 92(1), 181-197.

[52] Young, E.R. (2010), Solving the Incomplete Markets Model with Aggregate Uncertainty Using the Krusell-Smith Algorithm and Non-stochastic Simulations, Journal of Economic Dynamics and Control, 34(1), 36-41. 


\section{Appendix A: Empirical evidence and data sources}

1. Evidence on capital reallocation

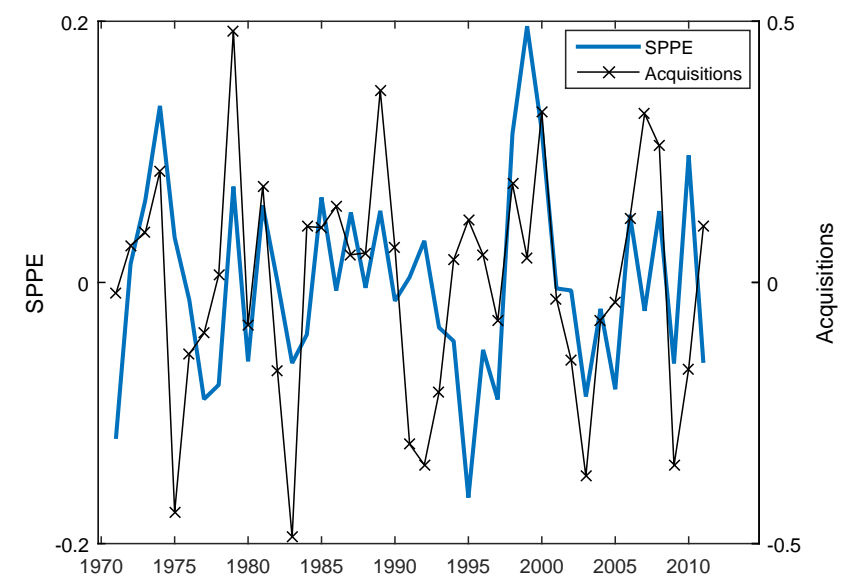

Figure 11: Components of capital reallocation (cyclical components)

Log-deviations from HP trend (smoothing parameter $=6.25$ ) of (i) Sales of Property, Plants and Equipment, (ii) Acquisitions. Variables deflated using the US GDP deflator, yearly frequency.

\begin{tabular}{|c|c|c|c|}
\hline Statistic & Reall & SPPE & Acq \\
\hline \hline$\sigma()$. & $.159(.011)$ & $.075(.01)$ & $.221(.016)$ \\
\hline $\operatorname{corr}(.$, GDP $)$ & $.712(.062)$ & $.305(.095)$ & $.765(.044)$ \\
\hline
\end{tabular}

Table 6: Business-cycle properties of capital reallocation

Standard deviations and correlation coefficients with US GDP of the cyclical components of capital reallocation and its two components (SPPE and Acquisitions). All variables in logs, deflated using GDP deflator and HP-filtered (smoothing parameter $=6.25$ ). Standard errors, in parentheses, are computed using a GMM Newey-West (1987) procedure.

2. Evidence on prices in secondary markets: Aircraft. Starting with a dataset on the value of all Western-built commercial aircraft from 1967 to 2009, I construct a price index of used and new aircraft. This dataset was compiled by Aircraft Values, a UK-based specialized consulting company that evaluates aircraft based on actual transactions prices for which the seller was not bankrupt. It includes prices of all the different vintages of 38 types of aircraft, from their first production year onward. The observation unit is an aircraft of type $j$, vintage $v$ in year $t$, with price $p_{j v t}$. To construct the index, 


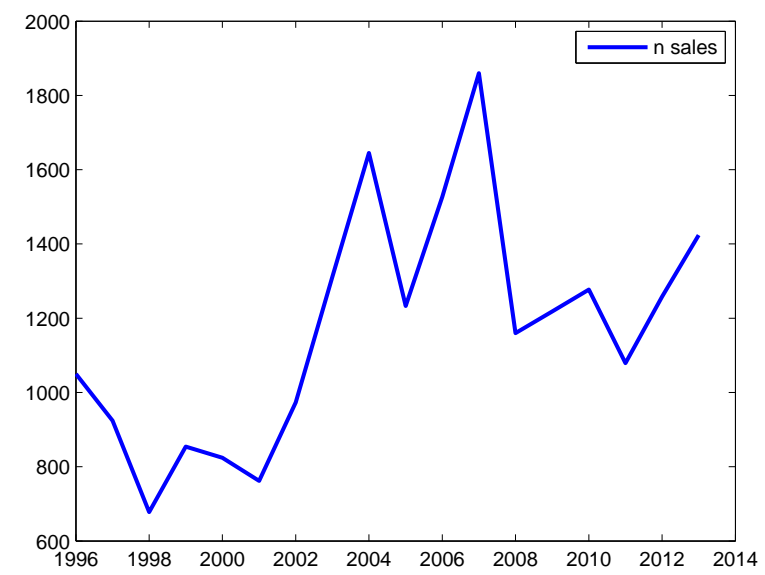

Figure 12: Ships: number of second-hand sales

Global yearly sales of second-hand commercial ships. Source: Clarkson

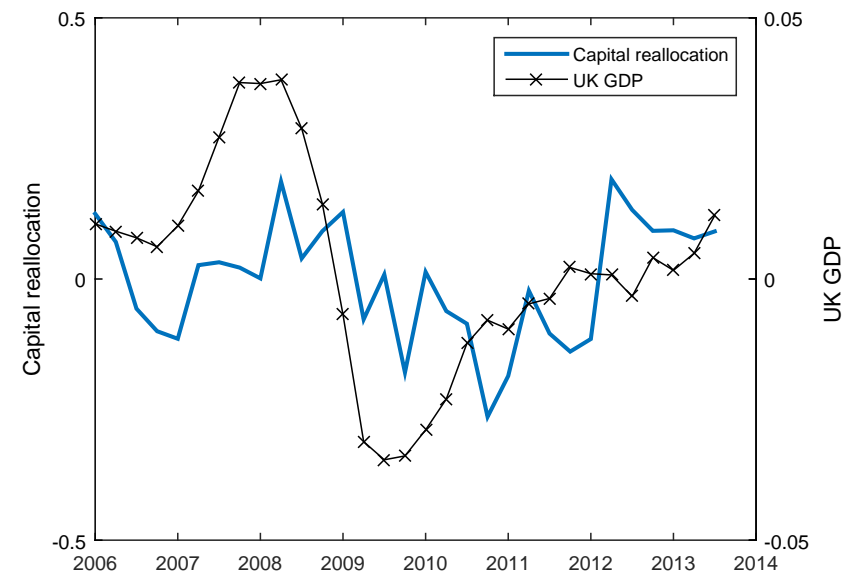

Figure 13: Capital reallocation in UK during the Great Recession

Cyclical components of quarterly sales of used equipment and UK real GDP, deflated using the GDP deflator. 

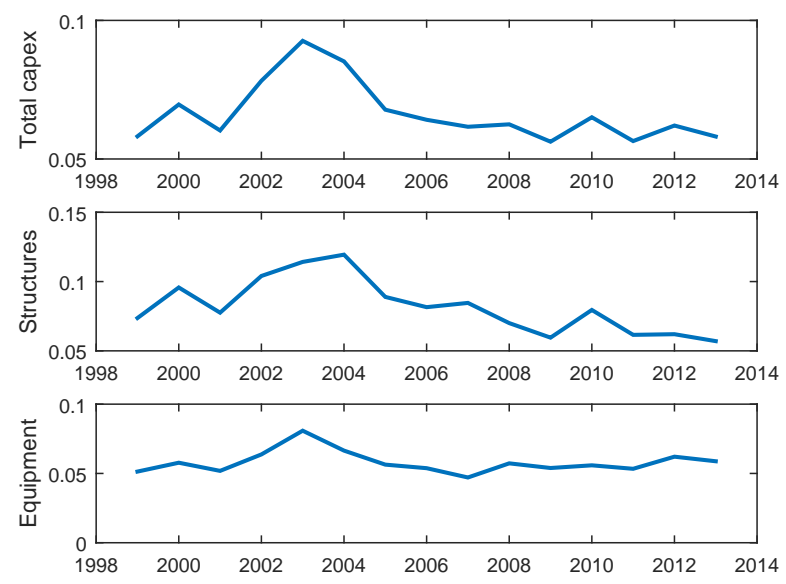

Figure 14: Share of used capital in capital expenditures

Annual Capital Expenditures Survey data on the share of used capital in total capital expenditures (first panel) and its two components: structures (second panel) and equipment (third panel). These data do not include Acquisitions.

I divide the data into prices of new aircraft $(v=t)$ and prices of used aircraft $(v<t)$. I deflate all prices using the US GDP deflator. Then, I create dummy variables for year, age and type (and interaction terms) and run a regression of $\log \left(p_{j v t}\right)$ on these dummies. In each subsample (new and used), the coefficients on the time dummies are the quality-age-adjusted price index of aircraft. Finally, I detrend the series using an HP filter, with a smoothing coefficient of $6.25 .{ }^{17}$

Ships. I gather price series for new and used ships for the period 1996-2013 from Clarkson and VesselsValue, two specialized companies that collect transaction prices and assess existing ships' market value. It is interesting to observe that prices and quantities traded fell contemporaneously in 2008, and that the price index of used ships is more volatile than the price index of new ships (Figures 2 and 12). Similar to the points made about aircraft in Section 2, in the case of ships, the resale price of more specific models (e.g. the very heavy and large Capesize bulk carrier) in terms of possible routes also grew more strongly in the period 2006-2008 and then fell by a larger fraction towards the end of 2008 than the price of less specific ones (e.g. the more flexible and small Handysize bulk carrier). This is shown in Figure 15.

Vehicles. In the case of vehicles and trucks, one can compare two separate separate CPI series, one for new (CPI new vehicles) and one for used (CPI used cars and trucks)

\footnotetext{
${ }^{17}$ Robustness exercises with different smoothing parameters lead to very similar results.
} 
in the sample 1953-2013. It emerges that the price of used vehicles is more volatile and more procyclical than that of new ones, which is actually acyclical (its correlation with GDP is statistically insignificant). The volatility of prices of used vehicles is smaller than that of aircraft and ships, arguably because vehicles are a less specific type of asset. Hence, this difference in volatilities is broadly consistent with a theory based on capital specificity.

Construction equipment. Edgerton (2011) constructs an index of the price of used construction machinery by collecting data on auctions in which this equipment is reallocated across US construction firms in the time period 1994-2011. The index is constructed following the same procedure described for aircraft above (regressing prices on observable characteristics and time fixed effects). The price of used construction equipment fell by more than the corresponding PPI (price index of new construction machinery) both in the 2001 and in the 2009 recession and was, in general, significantly more volatile. In particular in 2009, the index of used construction equipment was more than $15 \%$ below trend, while the corresponding PPI of new construction machinery was slightly above trend.

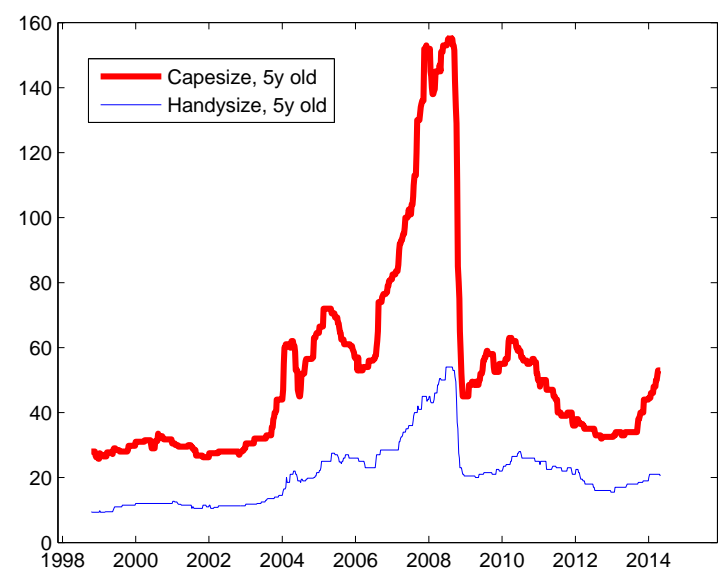

Figure 15: Ships: price of used Capesize and used Handysize

Prices in million $\$$ of second-hand 5 year-old Capesize (more specific) and Handysize (less specific). Weekly frequency: estimated values based on actual transactions and shipping market information. 
Data sources. Data on capital reallocation in the US come from the Compustat dataset and have been kindly made available by Andrea Eisfeldt on her personal webpage. Data on the share of used capital in capital expenditures come from the Annual Capital Expenditures Survey of the Census Bureau. Data on sales of used equipment in the UK come from the Office for National Statistics (ONS) Survey of Capital Expenditures. Data on aircraft prices are compiled by Aircraft Values. Data on commercial ships are compiled by Clarkson and VesselsValue. The price index for used commercial equipment was constructed by Edgerton (2011) using auction prices. Data on US GDP, GDP Deflator, CPI, CPI for new and used vehicles, as well as PPI for the construction sector, come from the US Bureau of Economic Analysis and the US Bureau of Labor Statistics. Data on UK GDP and GDP deflator come from the ONS. 


\section{Appendix B: Proof of Proposition 1}

(i) By equating (5) and (6), the market-clearing condition for used capital can be written as follows:

$$
G(q, z, \epsilon) \equiv \theta(q) \int_{s^{I}}\left[\left(\frac{\alpha z s}{Q(q)}\right)^{\frac{1}{1-\alpha}}-k_{0}\right] d F(s)-\int^{s^{D}}\left[k_{0}-\left(\frac{\alpha z s}{q}\right)^{\frac{1}{1-\alpha}}\right] d F(s)=0 .
$$

where $s^{I}=\frac{Q(q)}{\alpha z k_{0}^{\alpha-1}}, s^{D}=\frac{q}{\alpha z k_{0}^{\alpha-1}}, Q(q)=\left[\eta+(1-\eta)(q+\gamma)^{1-\epsilon}\right]^{\frac{1}{1-\epsilon}}, \theta(q)=\left(\frac{q+\gamma}{Q(q)}\right)^{-\epsilon}(1-\eta)$ is the ratio of used investment to total investment for investing firms, and I have left implicit the dependence of $\theta, q$ and $Q$ on $\epsilon$. Equation (25) defines the market-clearing price $q$ as an implicit function of the aggregate productivity parameter $z$ and the elasticity of substitution between new and used capital $\epsilon$. We can obtain the derivative of $q$ with respect to $z$ by applying the Implicit Function Theorem to function $G$, and we get ${ }^{18}$

$$
\frac{d q}{d z}=-\frac{G_{z}}{G_{q}}
$$

with

$$
G_{z}=\frac{\theta}{(1-\alpha) z} \int_{s^{I}}\left(\frac{\alpha z s}{Q}\right)^{\frac{1}{1-\alpha}} d F(s)+\frac{1}{(1-\alpha) z} \int^{s^{D}}\left(\frac{\alpha z s}{q}\right)^{\frac{1}{1-\alpha}} d F(s)
$$

and

$G_{q}=\theta_{q} \int_{s^{I}}\left[\left(\frac{\alpha z s}{Q(q)}\right)^{\frac{1}{1-\alpha}}-k_{0}\right] d F(s)-\frac{\theta Q_{q}}{(1-\alpha) Q} \int_{s^{I}}\left(\frac{\alpha z s}{Q}\right)^{\frac{1}{1-\alpha}} d F(s)-\frac{1}{(1-\alpha) q} \int^{s^{D}}\left(\frac{\alpha z s}{q}\right)^{\frac{1}{1-\alpha}} d F(s)$

In applying Leibniz rule to derive these expressions, we do not need to worry about the derivatives of the end points $s^{D}$ and $s^{I}$ because, by their definition, the respective integrands are equal to zero when evaluated at these points. Note that $G_{z}$ is positive and $G_{q}$ is negative (as $\theta_{q}<0$ ), hence $q$ is increasing in $z$.

(ii) The elasticity of $q$ with respect to $z$, call it $\phi_{q, z}(\epsilon) \equiv \frac{d q}{d z} \frac{z}{q}$, is given by

$$
\phi_{q, z}(\epsilon)=\frac{\frac{\theta}{(1-\alpha)} \int_{s^{I}}\left(\frac{\alpha z s}{Q}\right)^{\frac{1}{1-\alpha}} d F(s)+\frac{1}{(1-\alpha)} \int^{s^{D}}\left(\frac{\alpha z s}{q}\right)^{\frac{1}{1-\alpha}} d F(s)}{-\theta_{q} q \int_{s^{I}}\left[\left(\frac{\alpha z s}{Q(q)}\right)^{\frac{1}{1-\alpha}}-k_{0}\right] d F(s)+\frac{\theta Q_{q} q}{(1-\alpha) Q} \int_{s^{I}}\left(\frac{\alpha z s}{Q}\right)^{\frac{1}{1-\alpha}} d F(s)+\frac{1}{(1-\alpha)} \int^{s^{D}}\left(\frac{\alpha z s}{q}\right)^{\frac{1}{1-\alpha}} d F(s)}
$$

\footnotetext{
${ }^{18}$ Notation: Call $f_{x}$ be the partial derivative of function $f$ with respect to argument $x$.
} 
Now, note that when $\epsilon=0$ (Leontief investment technology), the share of used capital to total investment becomes $\theta=1-\eta$, so that $\theta_{q}=0$, while the price index becomes $Q=\eta+(1-\eta)(q+\gamma)$, so that we get $Q_{q}=1-\eta$. Hence, we can write

$$
\phi_{q, z}(0)=\frac{(1-\eta) \int_{s^{I}}\left(\frac{\alpha z s}{Q}\right)^{\frac{1}{1-\alpha}} d F(s)+\int^{s^{D}}\left(\frac{\alpha z s}{q}\right)^{\frac{1}{1-\alpha}} d F(s)}{(1-\eta)^{2} \frac{q}{\eta+(1-\eta)(q+\gamma)} \int_{s^{I}}\left(\frac{\alpha z s}{Q}\right)^{\frac{1}{1-\alpha}} d F(s)+\int^{s^{D}}\left(\frac{\alpha z s}{q}\right)^{\frac{1}{1-\alpha}} d F(s)}
$$

and this establishes that $\phi_{q, z}(0)>1$ as $q<1 \Rightarrow(1-\eta) \frac{q}{\eta+(1-\eta)(q+\gamma)}<1$. Standard arguments can be used to show that $\phi_{q, z}$ is continuous.

To show that reallocation is increasing in $z$, it suffices to observe that the equilibrium supply of used capital $S_{\text {used }}^{*}$ - i.e. total reallocation - is a decreasing function of $\frac{z}{q}$ (as above, we can disregard the derivative of $s^{D}$ as the integrand is zero when evaluated at $\left.s^{D}\right)$ :

$$
S_{u s e d}^{*}=\int^{s^{D}}\left[k_{0}-\left(\frac{\alpha z s}{q}\right)^{\frac{1}{1-\alpha}}\right] d F(s)
$$

Thus, the sign of its derivative with respect to $z$ is the sign of $\phi_{q, z}-1$. This establishes that in the limit for sufficiently low elasticity of substitution between new and used capital, reallocation is increasing in $z$ - i.e. "procyclical". 


\section{Appendix C: Parameter values in the numerical example of the two-period model}

\begin{tabular}{|c|c|}
\hline Parameter & Value \\
\hline \hline$\beta$ & .95 \\
\hline$\delta$ & .1 \\
\hline$\alpha$ & .33 \\
\hline$z^{L}$ & .99 \\
\hline$z^{H}$ & 1.01 \\
\hline$\sigma_{i n n, s}$ & .05 \\
\hline$\rho_{s}$ & .8 \\
\hline$\eta$ & .7 \\
\hline$\epsilon$ & 5 \\
\hline$\gamma$ & .01 \\
\hline$\chi$ & .82 \\
\hline \multicolumn{2}{|c}{}
\end{tabular}

Table 7: Parameter values in two-period model 


\section{Appendix D: Algorithm for DSGE model and robustness exercises}

Algorithm. I solve the model using an extension of the method of Krusell and Smith (1998) and Khan and Thomas $(2008,2013)$, which takes care of non-trivial market clearing in the market for used capital. By non-trivial market clearing, Krusell and Smith (2006) mean that a price has to be solved for at each period during the simulation equating total supply and total demand (in this case for used capital), as opposed to what happens, for instance, in Krusell and Smith (1998), where the rental rate of capital can be easily solved for analytically given the predetermined level of aggregate capital.

- I approximate the distribution $m$ with its first moment, aggregate capital. Agents perceive a law of motion $\log \left(K^{\prime}\right)=\hat{\phi}_{0}+\hat{\phi}_{1} \log (K)+\hat{\phi}_{2} I\left(z^{H}\right)+\hat{\phi}_{3} \log (K) I\left(z^{H}\right)+\eta$, where $I\left(z^{H}\right)$ is an indicator function for the high-productivity aggregate state.

- I use third-order polynomials to approximate the perceived equilibrium price functions $\hat{q}\left(\log (K), I\left(z^{H}\right)\right), \hat{w}\left(\log (K), I\left(z^{H}\right)\right)$.

- Given these perceived laws of motion, I solve the individual firm's problem by value function iteration and obtain the policy functions, making them dependent on the current resale price $q_{t}$, that is I solve for the modified value function $\tilde{v}(k, s, z, K ; q)$, using $q$ as a parameter, meaning that agents think that only for the current period the resale price of capital is allowed to be off its Rational Expectation law of motion.

- I simulate a continuum of firms for 5000 periods using the simulation method of Young (2010) and update the price functions by explicitly imposing market clearing in the used capital market along the simulation.

- I compute consumption from the resource constraint and clear the labor market by using the household's first order condition that implies that consumption is proportional to the equilibrium wage

- I update the laws of motion using standard regression methods up to convergence.

- Accuracy checks. The $R^{2}$ of the regressions for future aggregate capital, price of used capital and wage are .9997, .9950 and .9976 respectively. Figure 16 illustrates the accuracy of the solution by showing the simulated series of aggregate capital (solid red line) and a forecast series constructed using the estimated coefficients of the law of motion and iterating on the forecast (blue crosses), as suggested by den Haan (2010). The figure shows that there are no large and systematic errors and that errors do not accumulate over time. 


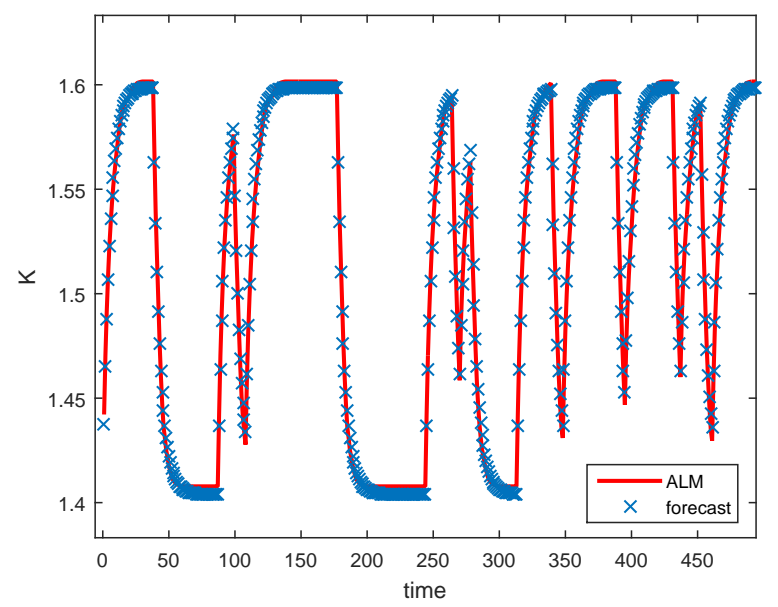

Figure 16: Actual Law of Motion and its forecast

Robustness exercises. The following tables report business-cycle statistics for different values of $\epsilon$ and HP-filter smoothing parameter.

\begin{tabular}{|c|c|c|c|c|c|c|c|}
\hline Statistic & $\mathrm{Y}$ & $\mathrm{C}$ & $\mathrm{I}$ & $\mathrm{K}$ & $\mathrm{N}$ & $\mathrm{q}$ & reall \\
\hline \hline mean & .595 & .495 & .099 & 1.516 & .335 & .948 & .042 \\
\hline$\sigma(.) / \sigma(Y)$ & 1.35 & .488 & 4.012 & .251 & .556 & .176 & 3.990 \\
\hline $\operatorname{corr}(., \mathrm{Y})$ & 1 & .903 & .958 & -.313 & .985 & .971 & .964 \\
\hline
\end{tabular}

Table 8: Business-cycle statistics: $\epsilon=1$ 


\begin{tabular}{|c|c|c|c|c|c|c|c|}
\hline Statistic & $\mathrm{Y}$ & $\mathrm{C}$ & $\mathrm{I}$ & $\mathrm{K}$ & $\mathrm{N}$ & $\mathrm{q}$ & reall \\
\hline \hline mean & .588 & .489 & .097 & 1.493 & .336 & .959 & .056 \\
\hline$\sigma(.) / \sigma(Y)$ & $(1.40)$ & .456 & 4.216 & .265 & .555 & .174 & 2.509 \\
\hline $\operatorname{corr}(., \mathrm{Y})$ & 1 & .923 & .941 & -.291 & .987 & .971 & .963 \\
\hline
\end{tabular}

Table 9: Business-cycle statistics: $\epsilon=10$

\begin{tabular}{|c|c|c|c|c|c|c|c|}
\hline Statistic & $\mathrm{Y}$ & $\mathrm{C}$ & $\mathrm{I}$ & $\mathrm{K}$ & $\mathrm{N}$ & $\mathrm{q}$ & reall \\
\hline \hline$\sigma(.) / \sigma(Y)$ & $(1.92)$ & .539 & 3.745 & .414 & .531 & .180 & 3.017 \\
\hline $\operatorname{corr}(., \mathrm{Y})$ & 1 & .927 & .953 & .045 & .956 & .918 & .963 \\
\hline
\end{tabular}

Table 10: Business-cycle statistics: baseline model, HP smoothing parameter $=100$

\section{Appendix E: Investment-specific shocks}

In the baseline version of the model, business cycles are driven by aggregate productivity shocks. However, a large literature emphasizes the importance of shocks to the productivity of investment as important drivers of aggregate fluctuations (e.g., Greenwood et al., 2000).

In this appendix, I argue that the main mechanism of endogenous irreversibility and capital reallocation is robust to this different source of business cycles. To see why this is the case, I first define the modified model. For simplicity, let the aggregate productivity parameter $z$ be constant and equal to 1 . Let $p_{t}$ be the relative price of new investment goods in terms of consumption. Investment goods are produced using the output good as input by a competitive firm. Hence shocks to the marginal cost of production of new investment goods translate into shocks to $p_{t}$. Let this shock follow a Markov chain with two values, $p_{t} \in\left\{p^{L}, p^{H}\right\}$.

The CES price index for a bundle of new and used investment is now

$$
Q_{t}=\left[\eta p_{t}^{1-\epsilon}+(1-\eta)\left(q_{t}+\gamma\right)^{1-\epsilon}\right]^{\frac{1}{1-\epsilon}}
$$

where $q_{t}$ is the relative price of used capital in terms of the consumption good.

Consider a persistent $1 \%$ increase from $p^{L}$ to $p^{H}$, illustrated in the first panel of Figure 17 (solid black line). When the shock hits the economy, new investment becomes more expensive, inducing a recession as is standard in the literature on investment-specific shock. Note that, in the present model, the shocks also leads to a fall in capital reallocation (second panel).

To see why this is the case, consider, first, the buyers in the market for used capital. The increase in the price for new investment goods has two effects of opposite signs on their demand for used capital: on the one hand, total investment is now more expensive $\left(Q_{t}\right.$ is higher), leading to a fall in demand for all kinds of investment goods. On the other hand, for 


\begin{tabular}{|c|c|c|c|c|c|c|c|}
\hline Statistic & $\mathrm{Y}$ & $\mathrm{C}$ & $\mathrm{I}$ & $\mathrm{K}$ & $\mathrm{N}$ & $\mathrm{q}$ & reall \\
\hline \hline$\sigma(.) / \sigma(Y)$ & $(2.00)$ & .497 & 4.378 & .441 & .581 & 0 & 1.119 \\
\hline $\operatorname{corr}(., \mathrm{Y})$ & 1 & .850 & .929 & .080 & .952 & 0 & -.613 \\
\hline
\end{tabular}

Table 11: Business-cycle statistics: constant $q$, HP smoothing parameter $=100$

\begin{tabular}{|c|c|c|}
\hline Model & $\sigma_{\text {inn }, I / K}$ & $\rho_{I / K}$ \\
\hline \hline Constant $q$ & .008 & .660 \\
\hline Baseline & .007 & .724 \\
\hline \hline Data & .008 & .695 \\
\hline
\end{tabular}

Table 12: Volatility and autocorrelation of aggregate investment rate

a given total investment, firms are willing to partially substitute from new to used investment goods, leading to an increase in demand for used goods. It turns out that for the calibrated elasticity of substitution between new and used investment, the first effect dominates and demand for used capital falls. Hence, $q_{t}$ (first panel, dashed blue line) increases only gradually, with the result that $q_{t} / p_{t}$ is below its average for several periods.

For unproductive firms, when the shock hits, it is a bad time to sell assets: they know that the resale price is likely to increase and that they might have to rebuy some capital at a higher $Q_{t}$ if they receive a positive idiosyncratic shock in the near future. This implies that investment-specific shocks also induce a procyclical response of capital reallocation. 

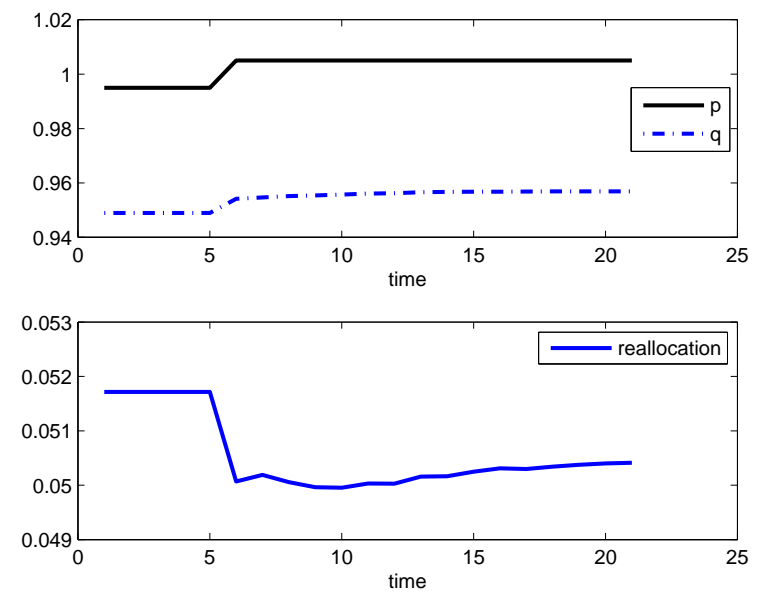

Figure 17: Investment-specific shock: investment prices and reallocation

Transition from long sequence $p_{t}=p^{L}$ to long sequence $p_{t}=p^{H}$. Response of the relative price of used capital (in terms of consumption) and capital reallocation (lower panel). 